\title{
معوقات نشر البحوث التربوية في المجلات العلمية
}

\author{
كمال مولوج \\ أستاذ محاضر قسم (أ)- كلية الاقتصاد- جامعة يحي فارس بالمدية - الجزائر \\ kmouloudj@yahoo.fr \\ فريدة مولوج \\ طالبة دكتوراه - كلية الآداب واللغات - جامعة علي لونيسي البليدة r - الجزائر \\ famouloudj@yahoo.com
}

هدفت الدراسة الحالية لتحديد الأهمية النسبية لمعوقات نشر البحوث التربوية في المجلات العلمية، ولتحقيق ذلك تم الاعتماد

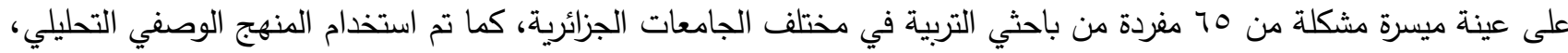

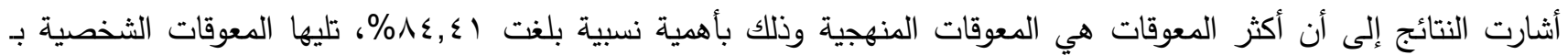

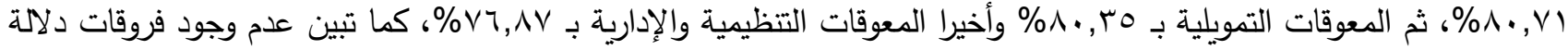
إحصائيا في الأهمية النسبية لطبيعة معوقات نشر البحوث التربوية في المجلات العبات العلمية تعزى للمتغيرات الوسيطية التالية: الرتبة

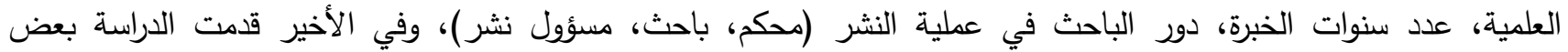
التوصيات التي قد تساعد في تلنيل صعوبات نشر البحوث التربوية في المجلات العلمية.

الكلمات المفتاحية: البحوث التربوية، المعوقات، المجلات العلمية، الجزائر . (c) (1)

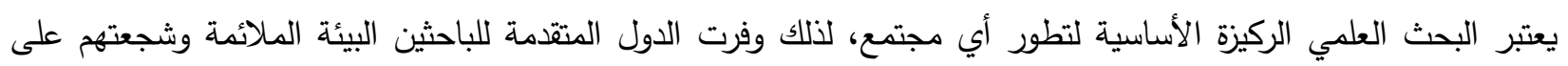

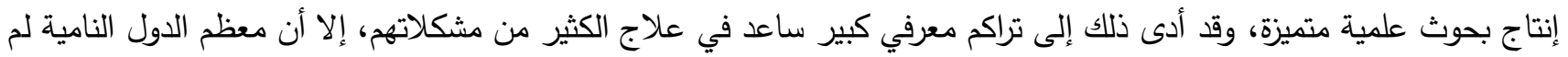

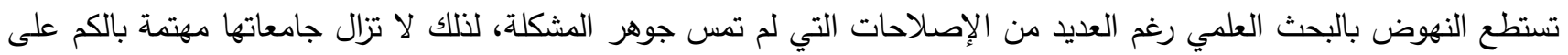

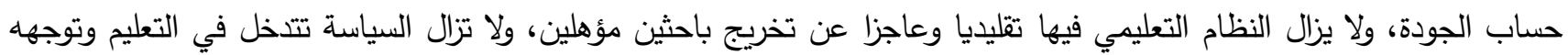

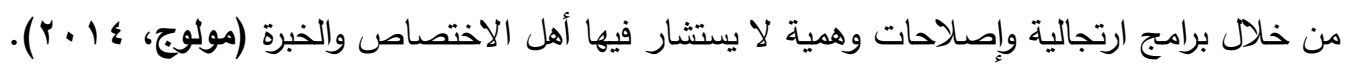

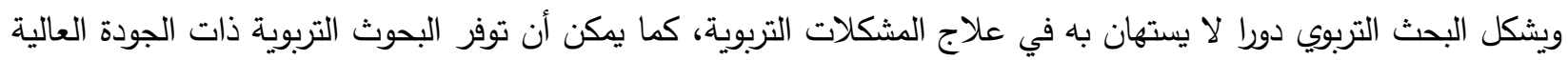

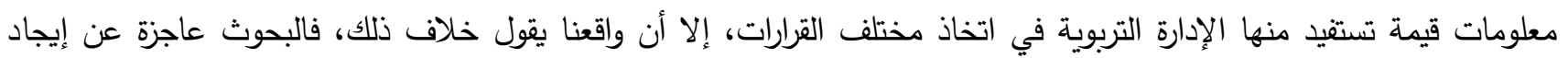

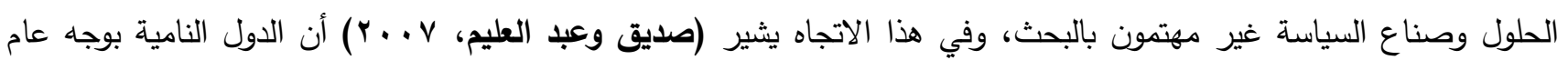

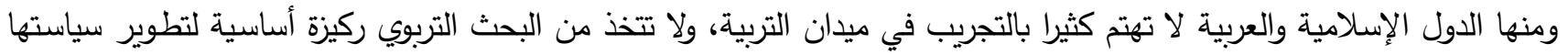

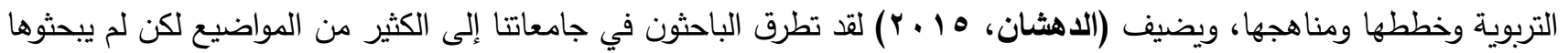


وإن اعتقدوا ذلك، كما أن البحوث التربوية أصبحت صدى مباشر لبعض اهتمامات أعضاء هيئة التدريس وليست جوابا لمشكلة أو قضية تربوية معينة تعاني منها البيئة التربوية العربية. كما يساهم النشر في تقييم مؤسسات التعليم العالي ويحسن من صورتها مما قد يزيد من إقبال الجمهور على خدماتها، في حين

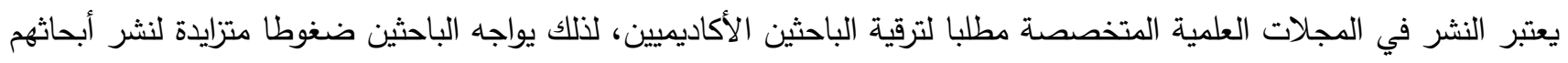

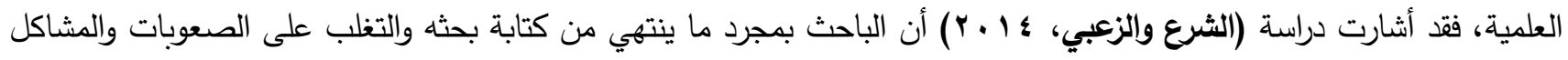
التي واجهته حتى يبدأ بمواجهة تحديات ومشكلات تتعلق بإجراءات نشر البحث كقلة المجلات المتخصصة؛ عدم توافر النزاهة والموضوعية في تقييم البحوث وقبولها للنشر في بعض المجلات التربوية؛ انخفاض مستوى كفاية المحكمين؛ تأخر بعض التهات المجلات بإخطار الباحث بوصول البحث أو تقييمه وقبوله أو رفضها.

\section{أولاً: الإطار العام للدراسة}

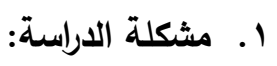

لا يزال دور الجامعات العربية تقليديا مركزا على التدريس ومهملا للإنتاج العلمي، فقد أصاب جامعاتتا عقما يتطلب

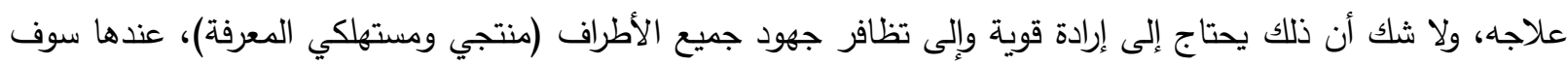

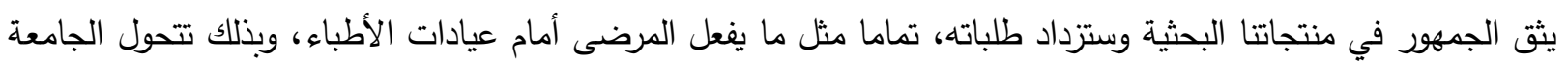
إلى شريك اجتماعي تقاسم المجتمع همومه ومشاكله. كما يشكل النشر في المجلات أهم قنوات اتصال الباحثين مع جماهيرهم، إلا أن الكثير من الباحثين في مختلف

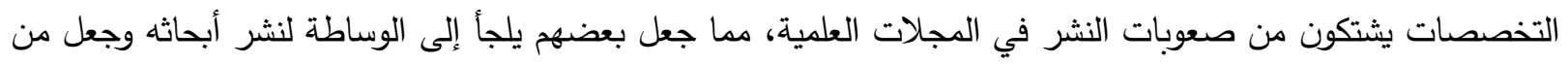

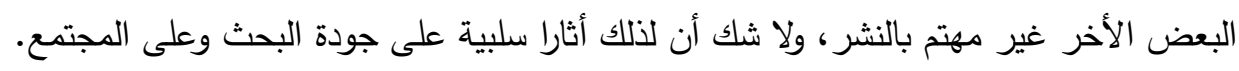

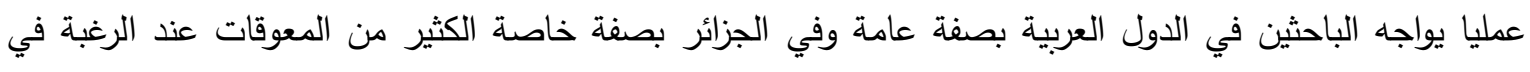
نشر أبحاثهم، فقد تتاولت العديد من الدراسات السابقة مشكلات ومعوقات نشر البحوث العلمية من زوايا مختلفة ( سيد،

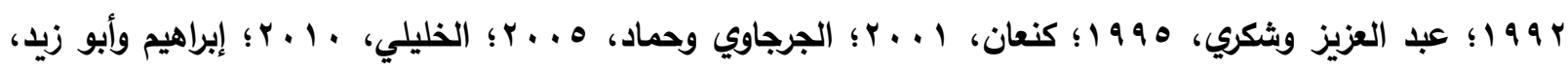

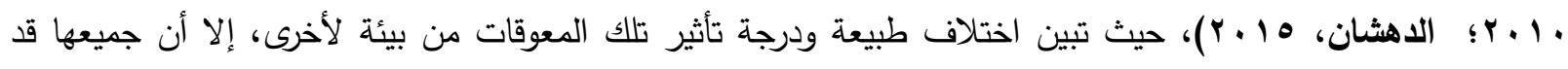

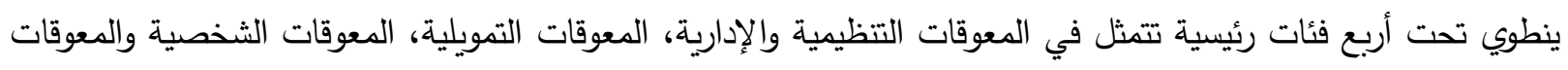
المنهجية، وعلى هذا الأساس تبحث هذه الدراسة في طبيعة المعوقات التي تعترض باحثي التئي التربية في الجزائر عند الرغبة في

$$
\text { نشر بحوثهم في المجلات العلمية؟. }
$$

\section{وعليه يمكن حصر عناصر مشكلة الدراسة بإيجاد أجوبة للأسئلة التالية:}

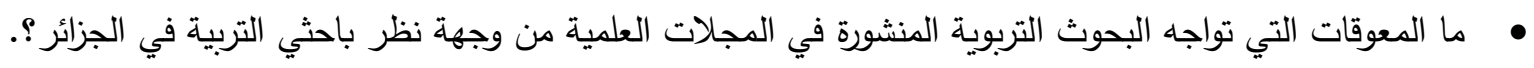

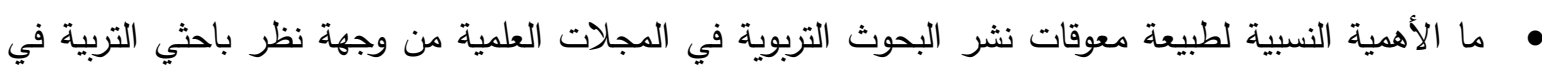

الجزائر

• هل يوجد اختلاف ذو دلالة إحصائية في الأهمية النسبية لطبيعة معوقات نشر البحوث التربوية في المجلات العلمية يعزى للمتغيرات الوسيطية التالية: الرتبة العلمية (أستاذ مساعد، أستاذ محاضر ، أستاذ)، عدد سنوات الخبرة (أقل من ست سنوات، من ست إلى اثني عشر سنة، أكثر من اثني عشر سنة)، دور الباحث في عملية النشر

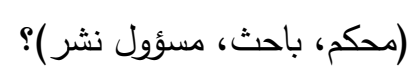

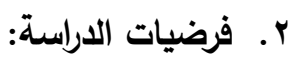

تم صياغة فرضيات الدراسة بالثكل العدمي كالاتي: الفرضية الرئيسية الأولى: 
Ho1: لا تختلف الأهمية النسبية لطبيعة معوقات نشر البحوث التربوية في المجلات العلمية من وجهة نظر باحثي التربية في الجزائر وتندرج تحت هذه الفرضية الفرضيات الفرعية التالية:

Ho11: لا تختلف الأهمية النسبية للمعوقات التظيمية والإدارية لنشر البحوث التربوية في المجلات العلمية من وجهة نظر باحثي التربية في الجزائر .

Ho12: لا تختلف الأهمية النسبية للمعوقات التمويلية لنشر البحوث التربوية المنشورة في المجلات العلمية من وجهة نظر باحثي التربية في الجزائر. Ho13: لا تختلف الأهمية النسبية للمعوقات الشخصية لنشر البحوث التربوية المنشورة في المجلات العلمية من وجهة نظر باحثي التربية في الجزائر. Ho14: لا تختلف الأهمية النسبية للمعوقات المنهجية لنشر البحوث التربوية المنشورة في المجلات العلمية من وجهة نظر باحثي التربية في الجزائر . الفرضية الرئيسية الثانية:

Ho2: لا يوجد اختلاف ذو دلالة إحصائية في الأهمية النسبية لطبيعة معوقات نشر البحوث التربوية في المجلات العلمية

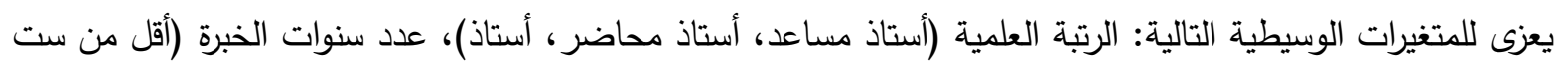
سنوات، من ست إلى اثني عشر سنة، أكثر من اثني عشر سنة)، دور الباحث في عملية النشر (محكم، باحث، مسؤول نشر)

\section{وتندرج تحت هذه الفرضية الفرضيات الفرعية التالية:}

Ho21: لا يوجد اختلاف ذو دلالة إحصائية في الأهمية النسبية لطبيعة معوقات نشر البحوث التربوية في المجلات

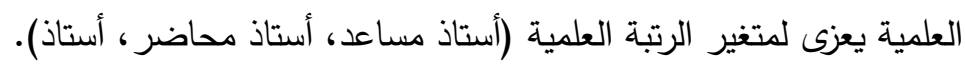

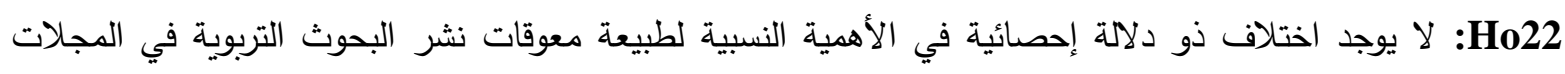
العلمية يعزى لمتغير عدد سنوات الخبرة (أقل من ست سنوات، من ست إلى اثني عشر سنة، أكثر من اثني عشر سنة).

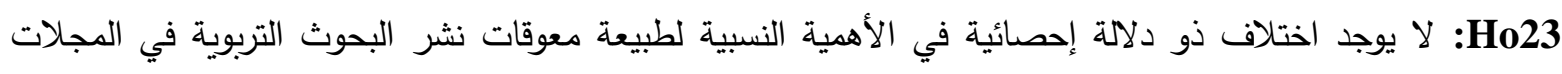
العلمية يعزى لمتغير دور الباحث في عملية النشر (محكم، باحث، مسؤول نشر ).

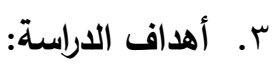

تهذف هذه الدراسة إلى تحقيق الاتي:

• التعرف على طبيعة المعوقات التي تواجه البحوث التربوية المنشورة في المجلات العلمية من وجهة نظر باحثي التربية في الجزائر . • تحديد الأهية النسبية لطبيعة معوقات نشر البحوث التربوية في المجلات العلمية من وجهة نظر باحثي التربية في الجزائر. تحديد مدى وجود فروقات في الأهمية النسبية لطبيعة معوقات نشر البحوث التربوية في المجلات العلمية تعزى للمتغيرات الوسيطية المذكورة سابقا. ع. أهمية الدراسة: تتبع الأهمية العلمية للدراسة من قلة الدراسات المتعلقة بمعوقات نشر البحوث العلمية، مما قد يجعل من هذه الدراسة تساهم في سد القليل من الفجوة البحثية في هذا الحقل المعرفي، كما يمكن لهذه الدراسة أن تحفز باحثين آخرين على إجراء

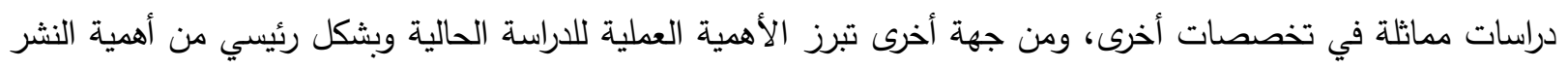


في المجلات بالنسبة للباحثين من أجل الترقية ولمؤسسات التعليم العالي من أجل التقييم والترتيب، ومن أهمية الدور الذي

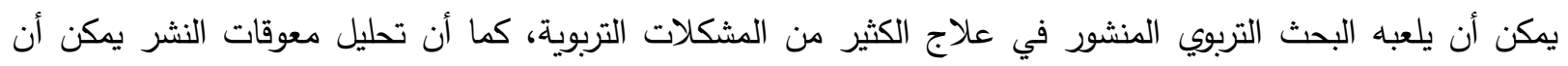
يساعد الجهات المسؤولة في إدراك أكثر المشكلات التي تعيق النشر ، وبالتالي إمكانية التخخل لتذليل تلك العقبات.

\section{๑. مجتمع وعينة الدراسة:}

بهدف الإحاطة بمختلف جوانب البحث قرر الباحثان أن يتكون مجتمع الدراسة من عدة شرائح من باحثي التربية شملت المحكمين والباحثين ومسؤولي النشر ببعض المجلات من مختلف الجامعات الجزائرية، ونظرا لصعوبة الاتصال والوصول إلى كل المفردات بسبب قيود التكلفة والوقت تم اختيار عينة ملائمة (convenience sample) حجمها 10

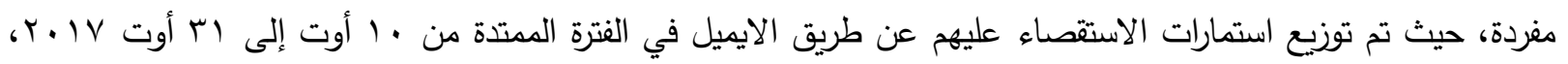
وقد بلغ عدد الاستمارات المسترجعة ج7 استمارة، تم إقصاء استمارة واحدة لعدم استيفائها لمتطلبات الدراسة، وبالتالي تم إجراء التحليل على 10 استمارة.

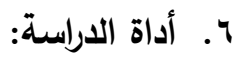
لجأ الباحثان إلى الاستبيان لجمع البيانات المتعلقة بالدراسة الميدانية، وذلك بالاعتماد على استمارة استبيان تم إعدادها في ضوء ما توصلت إليه الدراسات السابقة من نتائج وبناء على مقاييس مستخدمة في هذه الدراسات، وقد شملت الاستبانة

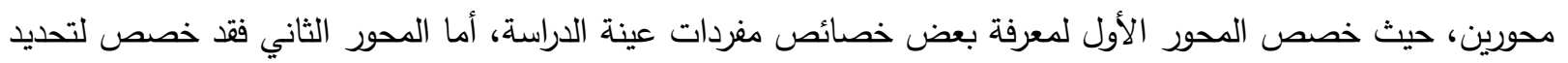

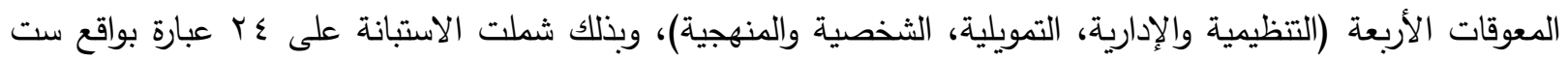

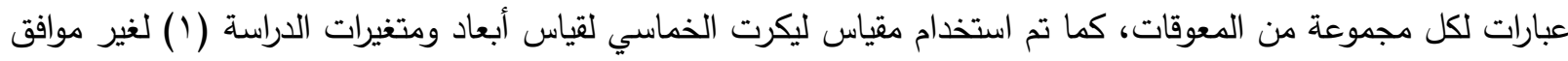
إطلاقا (0) لموافق تماما).

V تم التأكد من صدق أداة القياس بعرض الاستبيان على اثثين من المختصين للحكم على محتوى الأسئلة ومدى ملاءمتها وشموليتها للموضوع المبحوث، وبغرض التأكد من فهم مفردات العينة لأسئلة الاستبيان تم توزيع ثمان استمارات

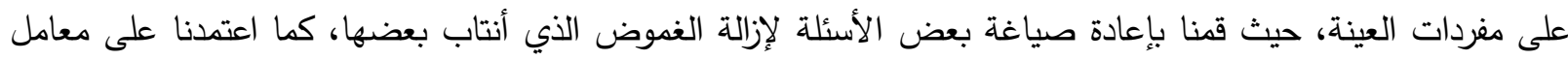

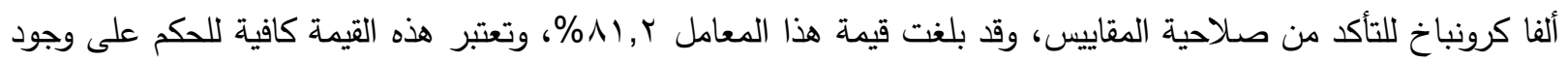

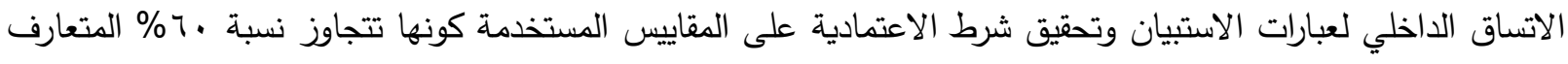

$$
\text { عليها، وهذا يعني أن المقاييس تتمتع بدلالات ثابتة ومقبولة. }
$$

^. المصطلحات الإجرائية للاراسة: معوقات النشر: كل العقبات أو المشكلات التي تعترض الباحث أثثاء رغبته في نشر بحثه في مجلة علمية، وتقاس إجرائيا

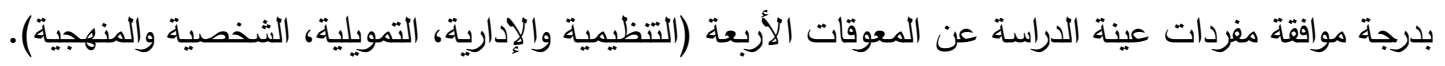
الأهمية النسبية للمعوقات: وزن ودرجة كل مجموعة من المعوقات، وقد تساهم تلك المعوقات بنسب متفاوتة أو متساوية في إعاقة الباحث أثناء رحلة نشر بحثه. 9 9. محددات الاراسة: • اقتصرت الدراسة الحالية على باحثي التربية في الجامعات الجزائرية، ولم تشمل باقي التخصصات والتي يمكن أن تكون نتائجها مختلفة عن نتائج هذا التخصص بحكم اختلاف الكثير من العوامل، ولهذا علاقة بعدم القدرة على تعميم النتائج المتوصل إليها على كل التخصصات. 
تم الاعتماد على أسلوب العينة الملائمة في اختيار المفردات، مما قد يحد من إمكانية تعميم نتائج هذه الدراسة ما لم تتفذ دراسات أخرى تؤيد نتائجها نتائج هذه الدراسة. • اقتصرت هذه الدراسة على البحث في معوقات نشر البحوث التربوية في المجلات العلمية، دون التعرض لمعوقات نشر لـاند الكتب العلمية، مما يتطلب إجراء دراسات ميدانية أخرى لاكتثاف معوقات أخرى.

\section{ثانياً: الإطار النظري والدراسات السابقة ا ـ الإطار المفاهيمي للبحث التربوي:}

يعرف (عبيدات، كايد وعبد الرحمان، ؟ . . ب) البحث العلمي بأنه "مجموعة من الخطوات المنظمة التي يقوم بها الإنسان مستخدما الأسلوب العلمي وقواعد الطريقة العلمية في سعيه لزيادة سيطرته على بيئته واكتثاف مظاهرها وتحديد

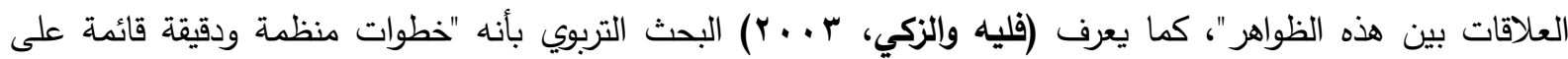
التقصي والدراسة الطويلة المتأنية بهدف اكتثاف أو وضع أسس وقواعد أو حل مشكلات في مجال التربية"، كما يعرفه (العنيزي، يونس، سلام والرشيدي، 999 199) بأنه "استقصاء دقيق هدفه وصف مشكلة موجودة في الميدان التربوي والتعليمي بهدف تحديدها وجمع المعلومات والبيانات المرتبطة بها، وتحليلها لاستخلاص النتائج ومحاولة تفسيرها والخروج بقواعد وقوانين يمكن استخدامها في علاج هذه المشكلات عند حدوثها"، ومن جهة أخرى يعرف (Day, 1983) الورقة البحثية بأنها "تقرير مكتوب ومنشور يصف نتائج البحث الأصلية". ووفقا لـ (نصار، ه 1 • Y) يحظى البحث التربوي بأهمية خاصة بوصفه يستهدف الوصول إلى الصورة المثلى لتربية الفرد الذي يشكل رأس المال الفكري في مجتمع المعرفة، من خلال ما يضطلع به البحث التربوي من تطوير للممارسات

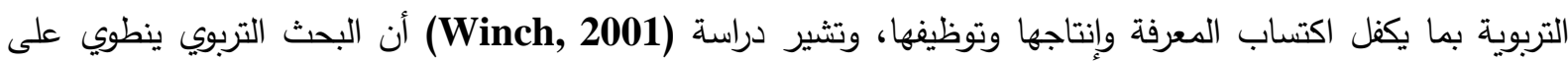

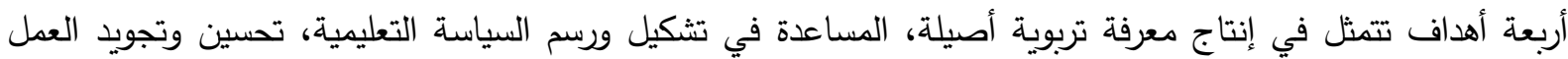
التربوي والإسهام في دفع عجلة التغيير والتتمية في المجتمع. عمليا يساعد البحث التربوي في تحديد فعالية طرق التعليم المستخدمة وفي الموازنة بين هذه الطرق واختيار وإنيار أفضلها كما يساعد في تحديد المستويات التعليمية المختلفة ومدى مناسبة المواد والبرامج التعليمية في سد الاحتياجات الثقافية والتربوية للفرد والمجتمع، كما يساعد في حسم الخلاف في كثير من المشكلات التربوية (مرسي، بهو (1)، ويضيف

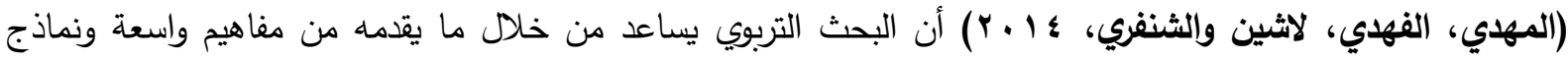

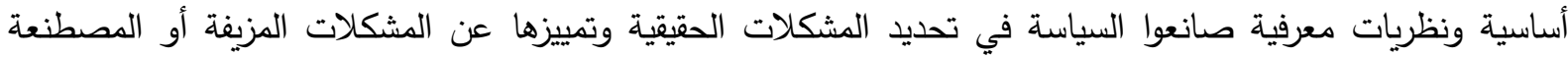
ويزيده قدرة على صياغة المشكلة ومن ثم إمكانية حلها بسهولة، كما تؤكد دراستهم على ضرورة ارتباط الخطط البحثية باحتياجات الواقع التربوي، ومن جهته يشير (Cohen, 2005) إلى وجود توتر بين باحثي التربية وصانعي السياسات،

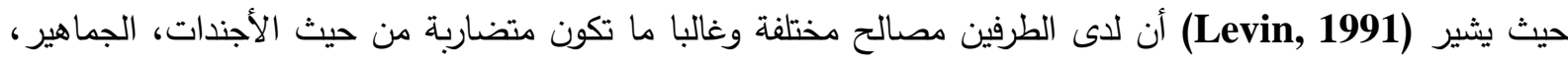

المقاييس الزمنية، المصطلحات والاهتمام بالموضوعية.

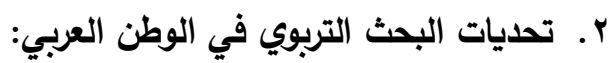

يشير (هانئ، V · . Pr) إلى إمكانية التمييز بين نوعين من البحوث التربوية، تمثل الفئة الأولى بحوثا أصيلة رصينة

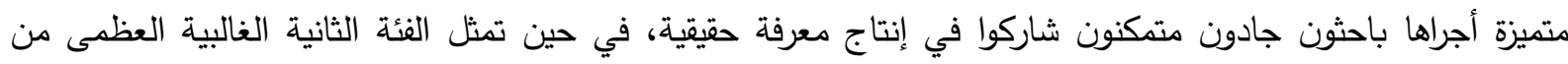

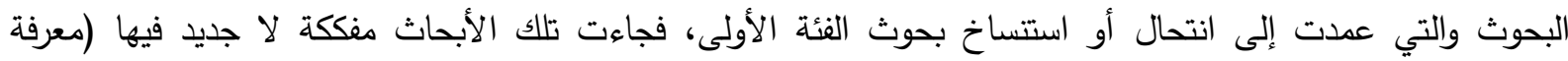
مستعملة أو مستهلكة). ووفقا لدراسة (الخليلي، 1 · ب) يمكن تقسيم التحديات التي تواجه البحث التربوي في الوطن العربي إلى أربع أنواع

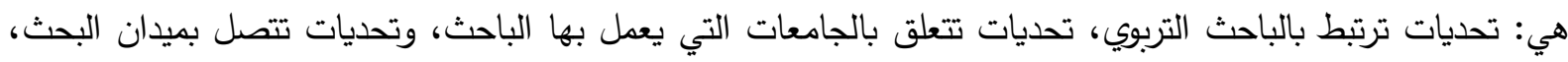


وتحديات ترتبط بالسياسات البحثية، كما أقرت دراسة (منتهى، ب ا • ץ) بكثرة وتتوع المعوقات التي تواجه البحث العلمي في جامعة بغداد، حيث أمكنها تصنيفها إلى ثلاث فئات هي المعوقات المادية، التنظيمية والفنية.

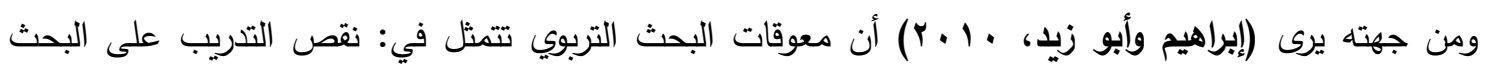

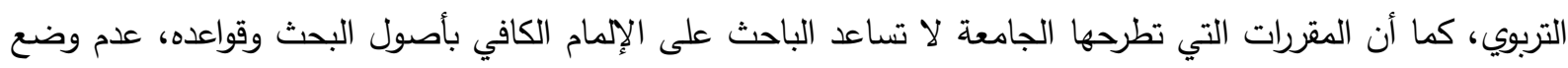

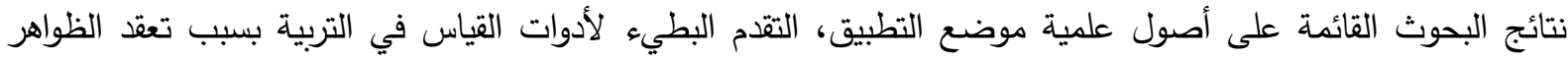

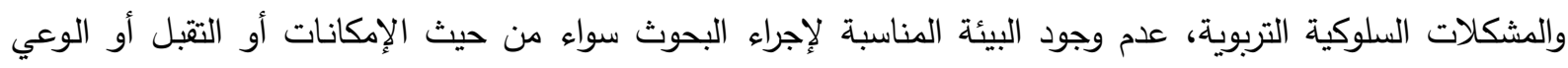
بأهميته.

ومن بين المعوقات التي أوردتها دراسة (المزين وسكيك، با. ب)، عدم وجود خريطة قومية للبحث العلمي والتربوي، حيث يتم فيها استعراض الأولويات وأهم المجالات التي تحتاج لإجراء البحوث لعلاج المشكلات المختلفة بأفضل

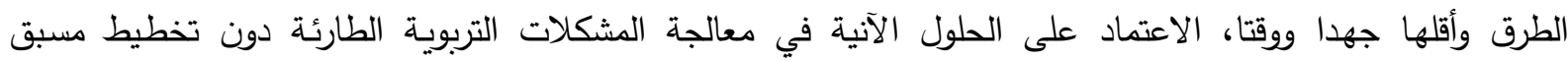

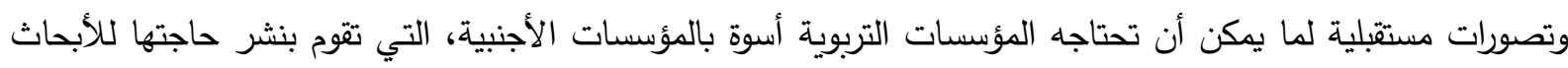
في موضوعات محددة لحل المشكلات التربوية المتوقع حدوثها، محدودية أدوات القياس المستخدمة من مقاييس الاتجاهات والميول والذكاء ومستويات التفكير والاستبيانات التي تعبأ في أحيان كثيرة بعدم مصداقية، مما يؤثر سلبا في نتائج البحث.

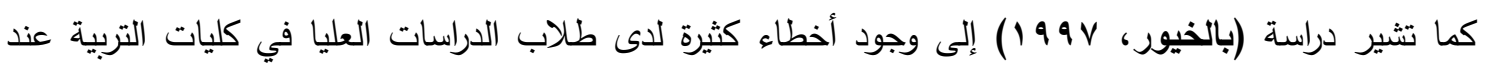

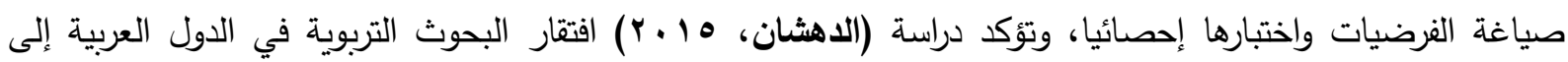

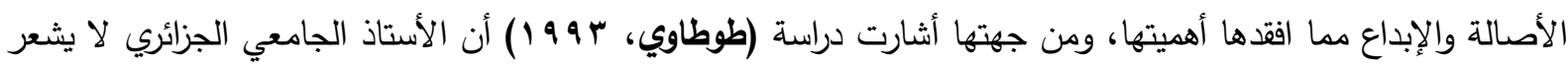

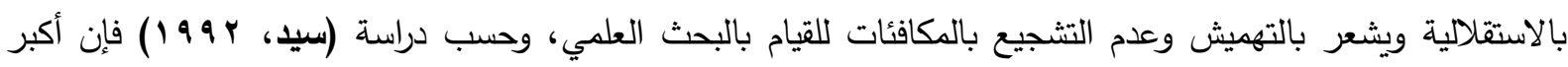

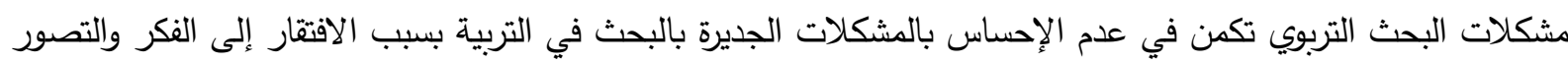
والنظرية، غياب الفلسفة العامة وتصدر النمطية، وسيادة الآلية وهيمنة التكرارية، وسيطرة الثكلية، والانتفاعية الشخصية على حساب الانتفاعية العامة لدى المؤسسات المعنية بالبحث التربوي.

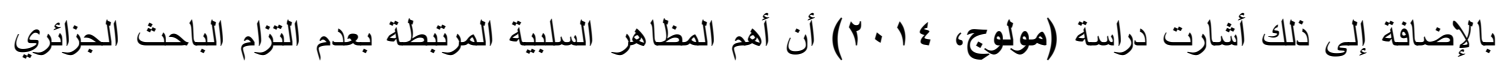
بمعايير السلوك الأخلاقي في أنشطة البحث العلمي تتمثل في المشاركة في ملتقيات وندوات علمية بأوراق بحثية على شكل محاضرات وليس بحوث علمية، زج بعض الباحثين لأسمائهم مع باحثين آخرين، الانضمام إلى فرق ومخابر البحث

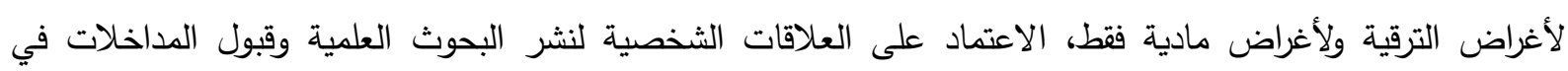
المؤتمرات، استغلال بعض الأساتذة للطلبة الذين يشرفون عليهم من خلادل مشاركتهم أبحاثهم.

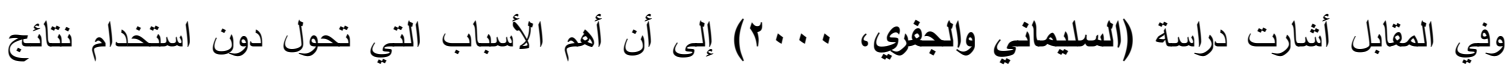

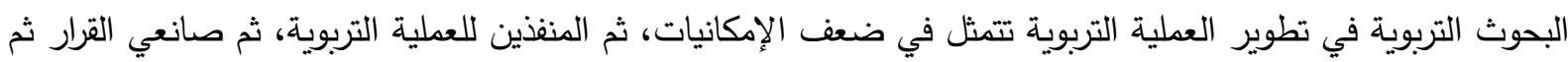

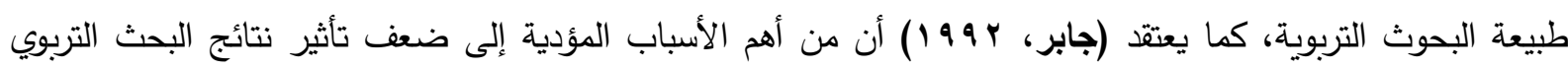

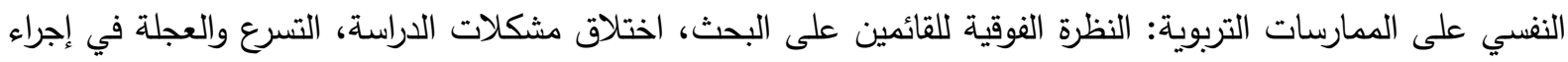
البحث، تقييد حركة البحث بمتطلبات الترقية، عزوف الباحثين الجادين عن البحث، ضعف التخطيط للبحث واختلاف وتتافر معايير تقييم البحث والحكم عليها. r. مشكلات نشر البحث التربوي في المجلات العلمية: تعد الدوريات التربوية المتخصصة من أهم قنوات نشر البحوث التربوية ومن أفضل المصادر التي يرجع إليها

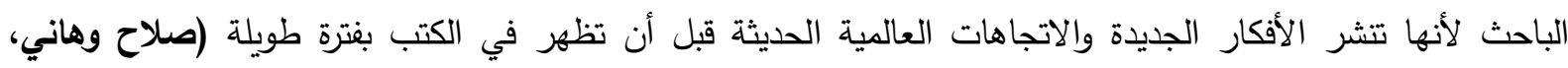


إن مشكلة غياب معايير علمية يحتكم إليها الباحثون في تقييم المجلات والأطروحات والرسائل العلمية يؤثر سلبا

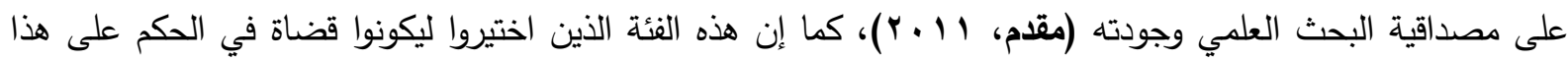

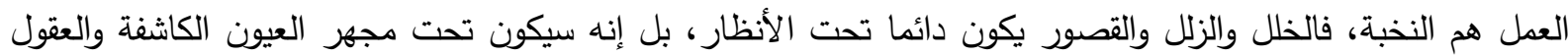

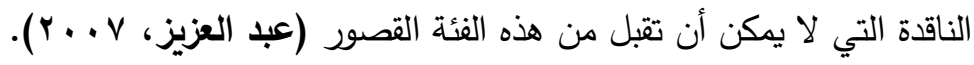

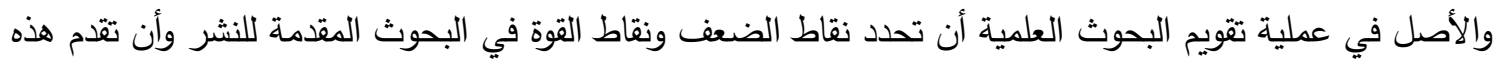
ضمن تقارير يعدها الأساتذة محكموا هذه البحوث وترسل إلى مسؤولي التحرير في المجلات الدورية المحكمة، وحتى يمكن لعملية التقويم هذه أن تسهم بفاعلية في تعزيز وتطوير القدرات والمهارات البحثية لدى الباحثين فلا بد أن تتاح لهؤلاء

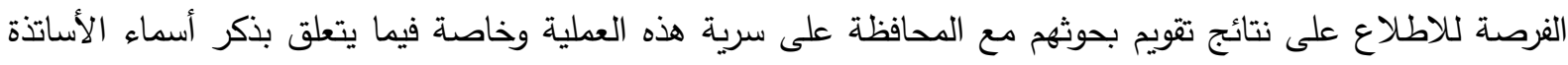

$$
\text { المحكمين منعا للإحراج (ناجي، ب . r. r). }
$$

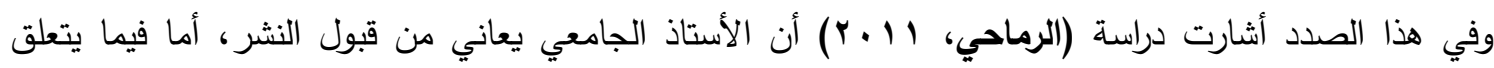

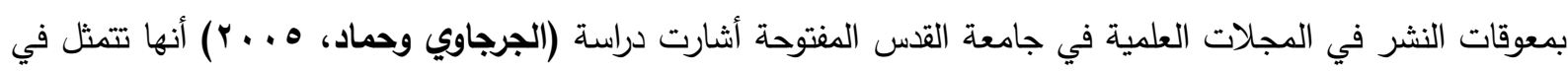
عدم وجود مجلات علمية متخصصة، بطء إجراءات التقييم للبحوث المرسلة للنشر، تأثير العلاقات الثخصية بين القائمين

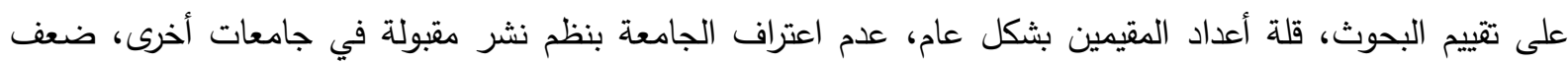

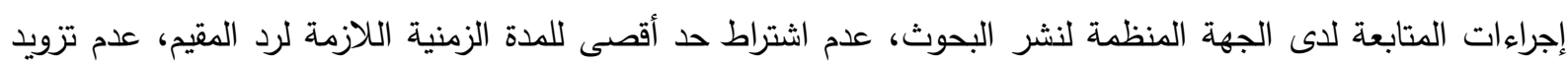

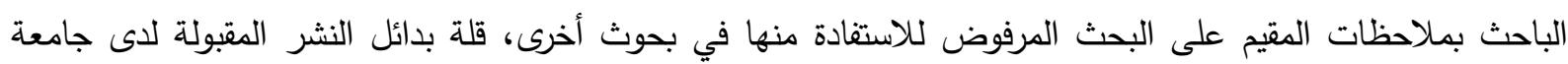
الباحث، عدم مساعدة الجامعة في تكاليف النشر (سوى المدعوم منها)، ارتفاع رسوم النشر .

ع. ـ الدراسات السابقة:

بعد مراجعة الأدبيات المتصلة بموضوع الدراسة، أمكن الحصول على الدراسات التالية: • دراسة (عبد العزيز وشكري، (9901) هدفت للتعرف على المشكلات التي تواجه البحث التربوي والنفسي في الوطن

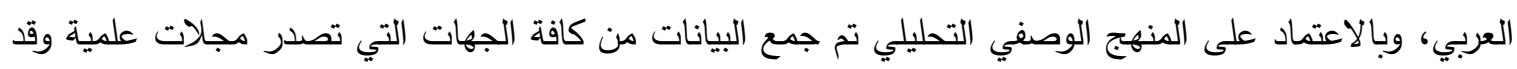
طلب منها تحديد عدد البحوث الواردة إليها للنشر؛ عدد البحوث المنشورة وغير المنشورة خلاد الخمس سنوات التوات الأخيرة، أثارت النتائج إلى وجود سبع مشكلات أساسية هي: عدم وجود سياسة واضحة للبحث التربوي، عدم توافر قاعدة بيانات، قلة الكوادر البحثية، ضعف التفاعل بين البحث التربوي والنظام التعليمي، عدم كفاية الموارد المالية المخصصة للبحث، ضعف التواصل بين المنتجين للبحث والمستهلكين له، عدم فعالية نتائج البحث في الممارسة التربوية. دراسة (كنعان، 1 . . ب) هدفت إلى التعرف على أهداف البحث العلمي ومعوقاته وسبل تطويره لاى أعضاء الهيئة التدريسية في كليات التربية، ولتحقيق ذلك تم الاعتماد على عينة مشكلة من •ـ هـ مفردة من أعضاء هيئة التدريس في

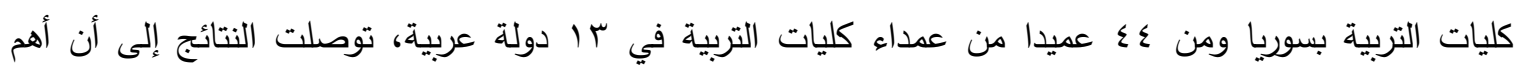
معوقات البحث العلمي التربوي في الجامعات العربية تتمثل في قلة التعاون بين الجامعة والجهات المستفيدة من البحث العلمي، نقص التمويل الكافي لدعم البحوث، قلة المراجع والمصادر الحديثة، قصور تطبيق خطة مركزية للبحوث العلمية على مستوى الجامعات والكليات، نقص الباحثين المساعدين والفنيين، قلة تعاون الزملاء في إجراء

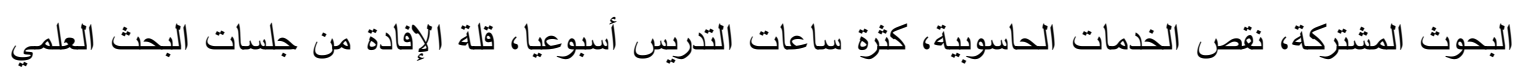
(المؤتمرات) وعدم توفر المناخ العلمي.

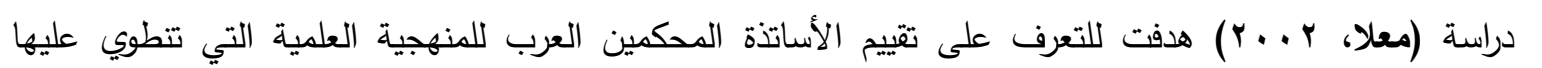
البحوث التسويقية الأكاديمية المقدمة للنشر في المجلات الدورية العربية، وقد تثكل مجتمع الدراسة من كافة الأساتذة 
المتخصصين في مجال التسويق الذين يعملون في أقسام الإدارة والتسويق في الجامعات الأعضاء في اتحاد

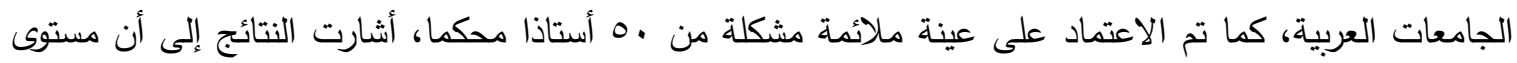

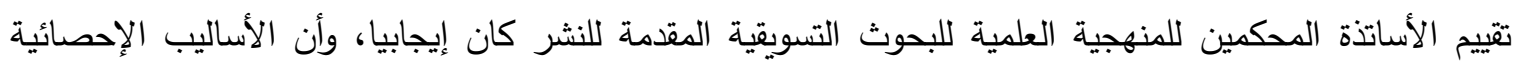
المستخدمة في تحليل البيانات كانت غير ملائمة، كما تبين أن المقاييس المستخدمة في قياس المتغيرات في البحوث

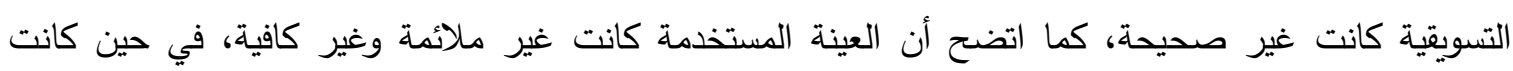

المراجعة الأدبية لموضوعات بحوث التسويق شاملة.

دراسة (الأغبري، ؟ . . †) هدفت للوقوف على واقع البحث العلمي في اليمن، وكانت دراسة نظرية استخدم فيها

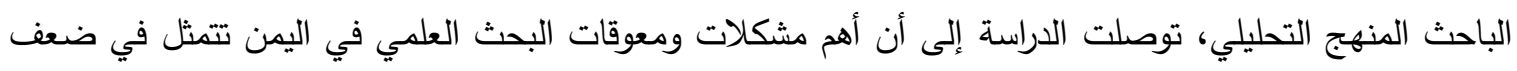

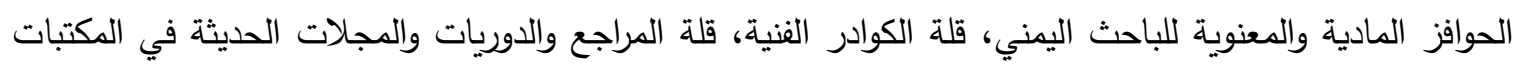
الجامعية، عدم توفر مستلزمات البحث العلمي اللازمة للتجارب العلمية، ثقل الأعباء التدريسية والمهام الإدارية التي ولي ولئي يشغلها بعض الباحثين، ضعف مستوى امتلاك بعض الباحثين لمهارات البحث العلمي ومنهجيته وأساليبه الإحصائية، ضعف الميزانية المخصصة للبحث، القيود الإدارية التي تحد من انجاز البحوث العلمية، صعوبة نشر البحوث وقئ وقلة الدوريات، عدم وجود سياسة وطنية بحثية مرسومة.

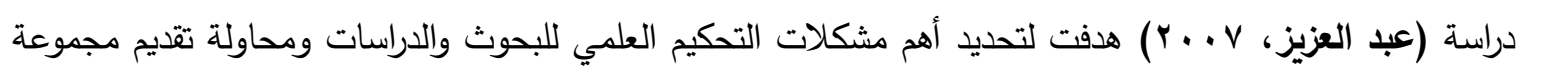

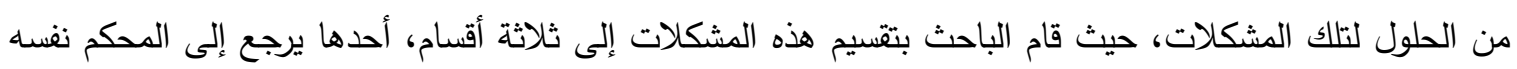

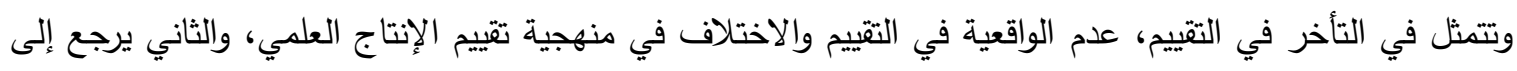

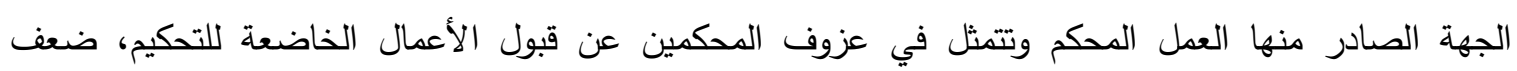

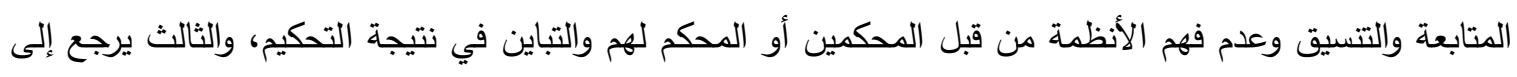

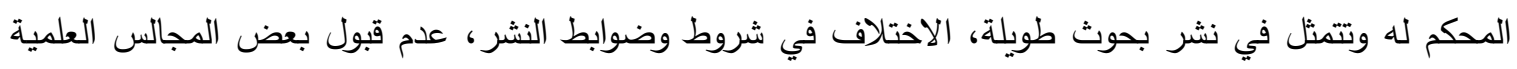
لبعض المجلات.

دراسة (المجيدل وشماس، • r) هدفت إلى تقصي المعوقات التي تواجه أعضاء الكيئة التدريسية في كلية التربية بصلالة وتحول دون إنجازهم لأبحاث علمية وانخراطه بالبحث العلمي، واشتملت عينة الدراسة على جميع أعضاء

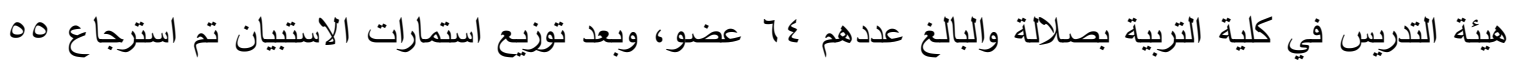

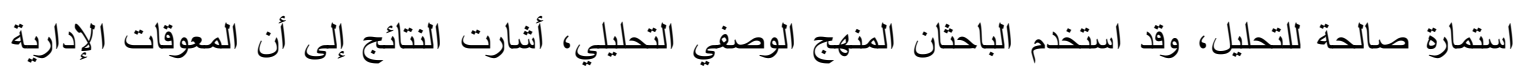
كانت هي الأشد وطأة على أعضاء الهيئة التدريسية في مجال البحث العلمي تليها المعوقات المادية ثم المعوقات الذاتية، كما تبين عدم فروق ذات دلالة تعزى لجنس ولتخصص الباحث فيما يتعلق بمعاناتهم من معوقات البحث العلمي، في حين ظهرت فروق دالة تتعق بسنوات الخبرة لصالح الأقل خبرة لجهة شدة معاناتهم من المعوقات.

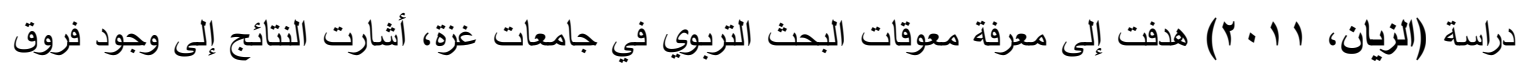
دلالة في تقديرات أعضاء هيئة التدريس لمعوقات البحث التربوي المادية والمعنوية تعزى لمتغير المؤهل العلمي

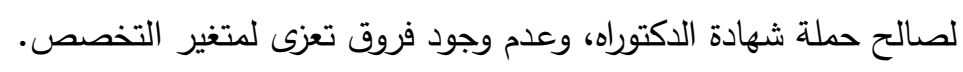

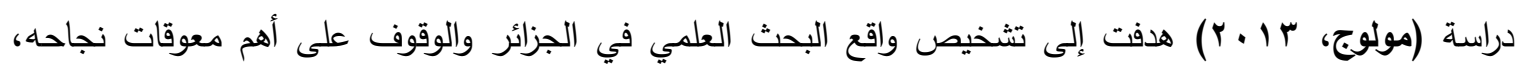

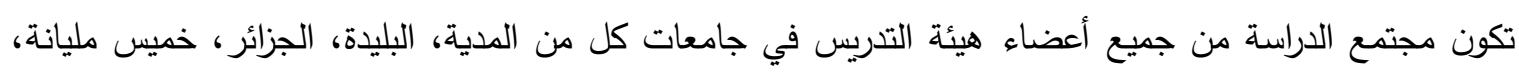

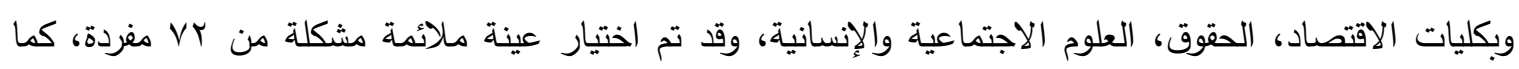

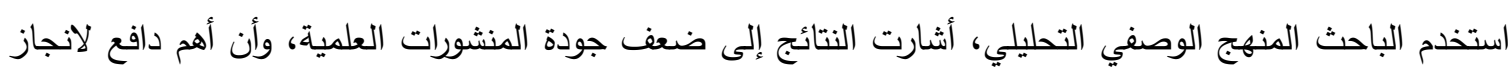

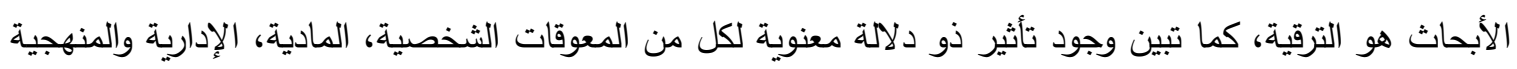


على جودة البحوث العلمية، في حين تبين عدم وجود فروق دالة معنويا في درجة تأثير تلك المعوقات على جودة

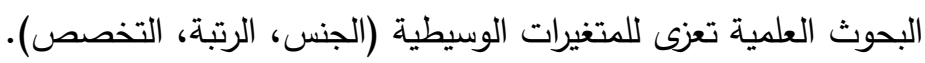

دراسة (الدهثان، 0 ـ ب م) هدفت لإلقاء نظرة نقدية لواقع البحث التربوي العربي، من خلال دراسة نظرية استخدم فيها

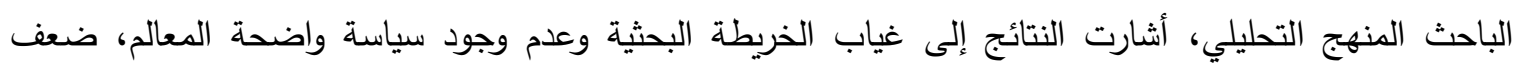

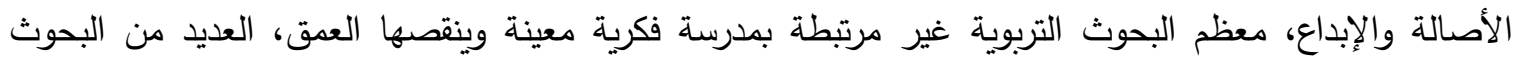
تخلو من دراسة مشكلات تربوية حقيقة وواقعية، التركيز على البحوث التربوية الكمية وغياب البحوث الكيفية أو موبه

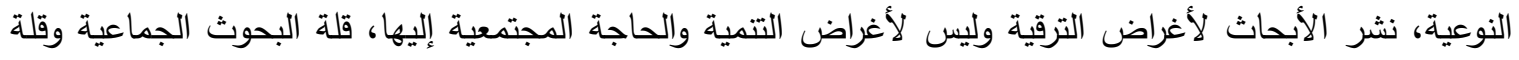
التعاون بين الباحثين (على مستوى الجامعة، القطر أو الإقليم)، المبالغة في استخدام الأرقام والوسائل الإحصائية

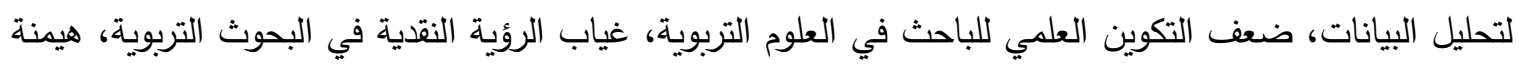

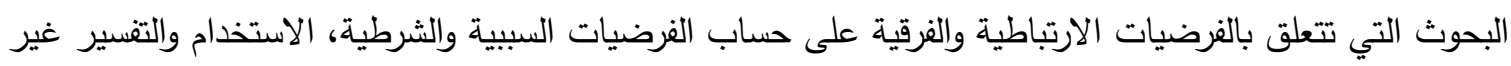

الاقيق لمصطلح الدلالة الإحصائية.

أجمعت معظم الدراسات السابقة التي تم الاطلاع عليها على وجود مشكلة حقيقية يعاني منها البحث العلمي التربوي

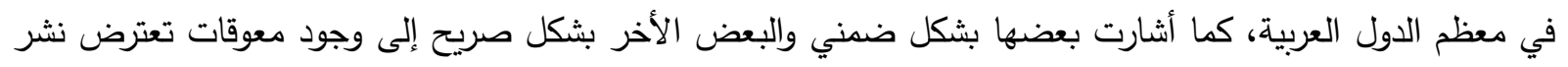

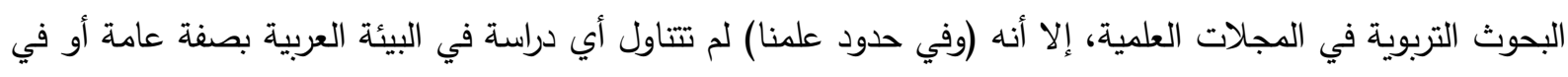

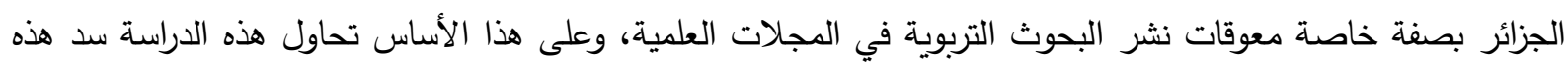

الفجوة البحثية.

\section{ثالثاً: تحليل ومناقشة نتائج الدراسة الميدانية}

لقد تم الاعتماد على الحزمة الإحصائية للعلوم الاجتماعية (SPSS) وذلك باستخدام التكرارات والنسب المئوية والمتوسطات الحسابية الموزونة، بالإضافة إلى اختبار (One sample t-test)، واختبار تحليل التباين الأحادي (One Way ANOVA) للتأكد من وجود أو عدم وجود فروقات في اختلاف درجات تأثير المعوقات المدروسة تعزى للمتغيرات الوسيطية. 1. - أ. وصف مفردات عينة الدراسة:

الجدول رقم (1) خصائص مفردات عينة الدارسة

\begin{tabular}{|c|c|c|c|}
\hline النسبة & العدد & الفئات & المتغيرات \\
\hline$\%$ \%ч, q. & $r \leq$ & أستاذ مساعد & \multirow{4}{*}{ الرتبة } \\
\hline$\% \leqslant \vee, V$. & M & أستاذ محاضر & \\
\hline$\% 10, \varepsilon$. & 1. & أستاذ & \\
\hline$\% 1 \ldots$ & 70 & المجموع & \\
\hline$\% r \cdot, \wedge$. & r. & أقل من 7 سنوات & \multirow{4}{*}{ الخبرة } \\
\hline \%rr,r. & YI & من 7 إلى ז' سنة & \\
\hline$\%$ \%ч, & $r \varepsilon$ & أكثر من r ا سنة & \\
\hline$\% 1 \ldots$ & 70 & المجموع & \\
\hline$\%$ \%ч, q. & $r \leq$ & محكم (مقيم) & \multirow{4}{*}{ الدور/الصفة } \\
\hline$\% \varepsilon,, \ldots$ & ז & باحث & \\
\hline$\% r r, 1$. & 10 & مسؤول النشر & \\
\hline$\% 1 \ldots$ & 70 & المجموع & \\
\hline
\end{tabular}

المصدر: نتائج الدراسة الميدانية 


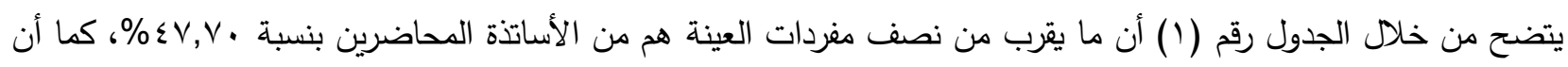
• .

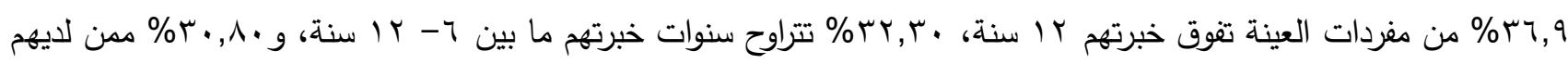

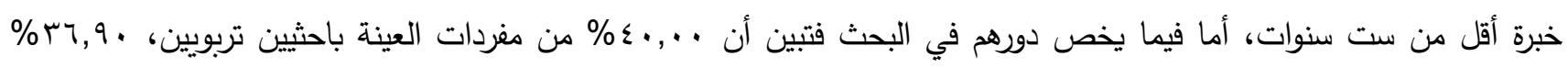

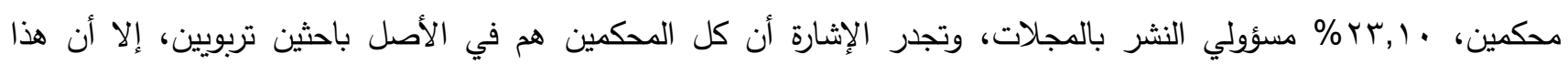
التصنيف لا يعكس سوى وضعهم أثناء فترة الاستجواب من خلال الطلب منهم تحديد أخر نشاط لهم (بحث أو تحكيم)، وعليه تبدو

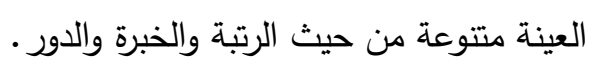

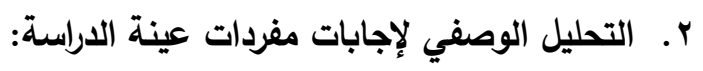

جدول رقم (ץ) المعوقات التنظيمية والإدارية للبحوث التربوية المنشورة في المجلات العلمية

\begin{tabular}{|c|c|c|c|c|}
\hline 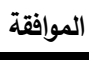 & الترتيب & المتوسط & المعوقات التنظيمية والإدارية & 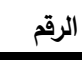 \\
\hline \multirow{6}{*}{ عالية } & 3 & 3,8923 & غياب معايير واضحة لقبول البحوث & 1 \\
\hline & 5 & 3,7538 & ضعف المتابعة والتتسيق للأعمال المحكمة & 2 \\
\hline & 2 & 3,9692 & التأخر في تقييم ونشر البحوث التربوية & 3 \\
\hline & 4 & 3,7692 & عدم الواقعية في تحكيم البحوث التربوية & 4 \\
\hline & 6 & 3,6923 & قلة المجلات التزبوية المتخصصة & 5 \\
\hline & 1 & 3,9846 & انتشار الاعتماد على الوساطة في نشر البحوث & 6 \\
\hline عالية & 4 & 3,8436 & \multicolumn{2}{|c|}{ المتوسط المرجح العام } \\
\hline
\end{tabular}

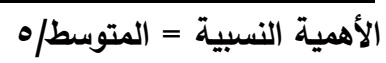

يتضح من خلال الجدول أعلاه أن أكثر المعوقات التنظيمية والإدارية تتمثل في "انتشار الاعتماد على الوساطة في نشر

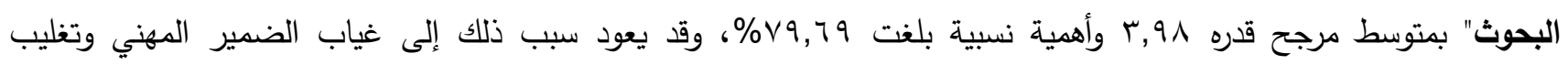
المصالح الثخصية على المصلحة العامة، ومن الأسباب غير المباشرة لانتشار هذه الظاهرة اشتراط بعض الثارة الكليات على الباحثين (من أجل الترقية) النشر في مجلات دون أخرى وهو ما شكل ضغطا على تلك المجلات مما استدعى الباحثين إلى اللجوء إلى الوساطة لنشر بحوثه وهي ظاهرة غير أخلاقية تتنافى مع قيم النشر المتعارف عليها عالميا، وعلى هذا الأساس أصبحت عملية

التحكيم شكلية فقط.

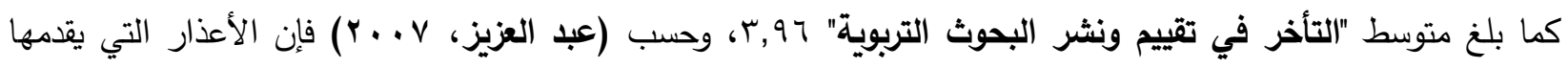

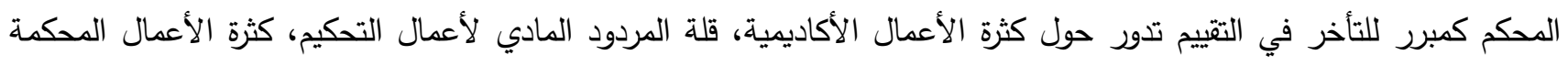

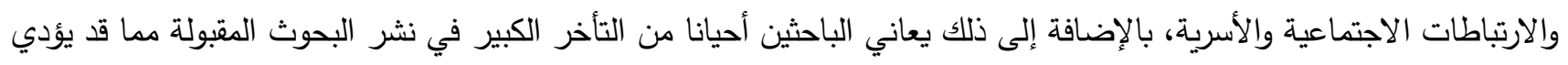
إلى تقادم النتائج المتوصل إليها، وقد يرجع التأخر في النشر إلى عدة أسباب منها تراكم عدد البحوث الإلى الواردة إلى المجلة، صدئ صدور

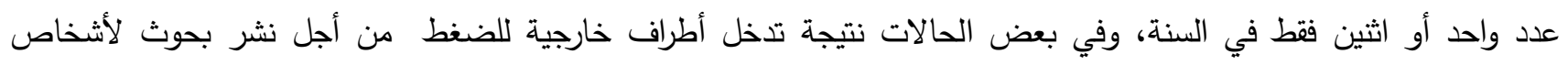

معينين.

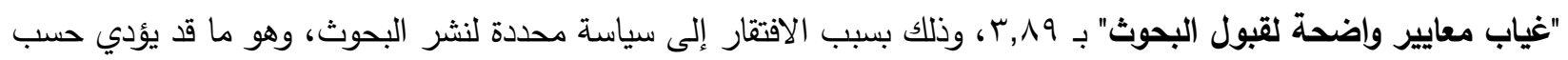

دراسة (عبد العزيز وشكري، 990 19) إلى تضارب بين البحوث من حيث محتواها، أو أهدافها أو نتائجها وأولوياتها.

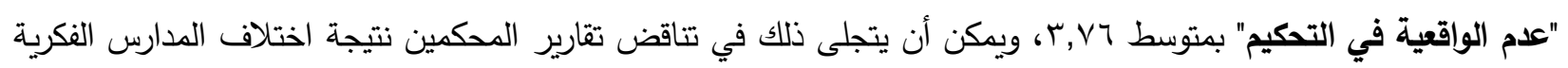

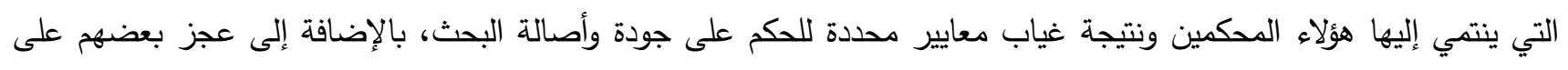

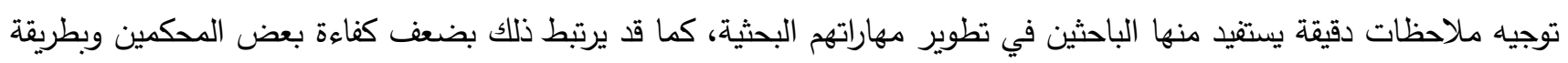


اختيار المجلة لهم، فكما هو معروف (في معظم الدول العربية) لا تدفع إدارات المجلات أي تعويضات للمحكمين، مما قد يؤثر على رغبة الجادين منهم في التعاون مع المجلة.

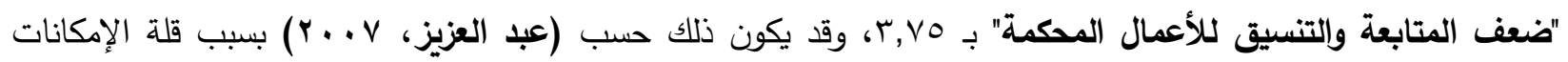
البشرية أو الضعف في التخطيط والتنظيم الإداري، فالدقة مثلا في عنوان المحكم وجهته، والتأكد من وصول الإنتاج العلمي إليه وليه

ومتابعته، وأخذ موافقته قبل مراسلته من الأعمال الإدارية والتتظيمية التي تعد من المشكلات التي تقع فيها بعض تلاد الته الجهات.

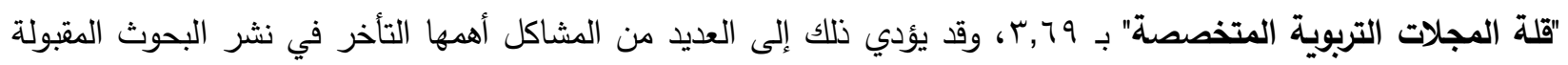
نتيجة التراكم الكبير للبحوث، كما يؤدي إلى ضغط بعض الأطراف على مسؤولي النشر بتلك المجلات لتمرير بحوث من خلال

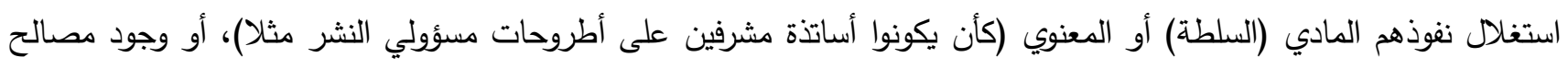
مشتركة كتواطؤ مسؤول النشر بمجلة معينة مع مسؤول آخر لمجلة أخرى من خلال تبادل كل منها النشر عند الأخر، واحتكار النشر من قبل مدير وأعضاء المجلة ومقربيهم.

جدول رقم (r) المعوقات التمويلية للبحوث التربوية المنشورة في المجلات العلمية

\begin{tabular}{|c|c|c|c|c|}
\hline 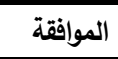 & 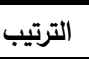 & المتوسط & المعوقات التمويلية & 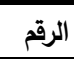 \\
\hline \multirow{6}{*}{ عالية } & 3 & 4,0462 & نقص التجهيزات والمعدات البحثية & 1 \\
\hline & 1 & 4,1538 & علم كفاية الميزانيات الدخصصة للمجلات العلمية & 2 \\
\hline & 5 & 3,8769 & عدم تَمين جهود مدير النشر وهيئة التحرير & 3 \\
\hline & 2 & 4,1385 & عدم تثمين جهود المحكمين & 4 \\
\hline & 6 & 3,8615 & عدم تثمين البحوث ذات الجودة العالية & 5 \\
\hline & 4 & 4,0308 & انعدام الرعاية التمويلية & 6 \\
\hline 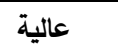 & 3 & 4,0179 & المتوسط المرجح العام & \\
\hline
\end{tabular}

يوضح الجدول رقم (r) أن أكثر المعوقات التمويلية تتمثل في "عدم كفاية الميزانيات المخصصة للمجلات العلمية" بمتوسط مرجح بلغ 10 ,ـ، ويؤدي ذلك إلى صدور المجلة مرة أو مرتين فقط في السنة، وصغر حجم المجلة (عدد صفحاتها)، بالإضافة إلى كائ

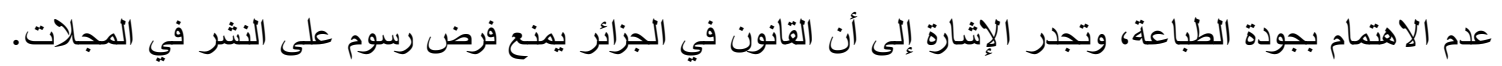

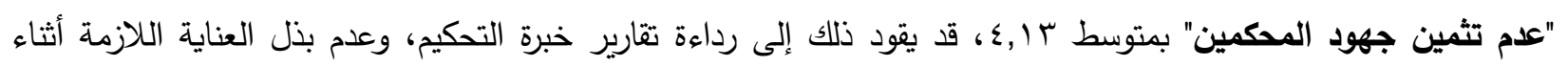

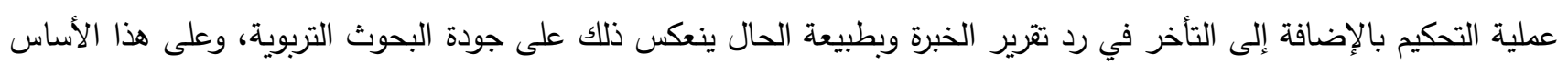
يعتبر تثمين جهود المحكين أمرا ضروريا كما يسمح لهيئة النشر الاتصال بباحثين عرب وأجانب للمشاركة في التحكيم وإثراء المجلة بآرائهم وانتقاداتهم.

"تقص التجهيزات والمعدات البحثية" بـ ع •,ـ؛، يتقق الجميع أن الكثير من البحوث التربوية التطبيقية تحتاج إلى تجهيزات

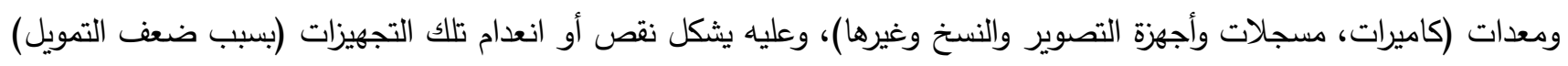
عائقا حقيقيا أمام الباحثين. "انعدام الرعاية التمويلية" بـ ب.,یء، سواءا رعاية البحوث التربوية أو المجلات من قبل المؤسسات المهتمة (حكومية أو

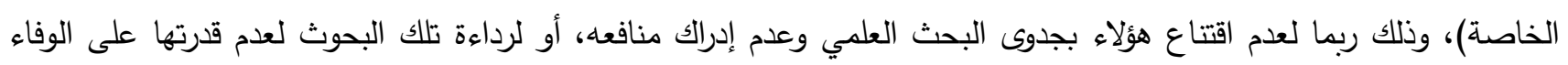

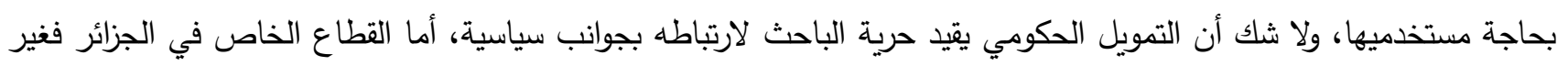
مهتم إطلاقا بالبحث العلمي ولا يشجعه إلا في مناسبات قليلة (كالمؤتمرات) وبمبالغ زهيدة.

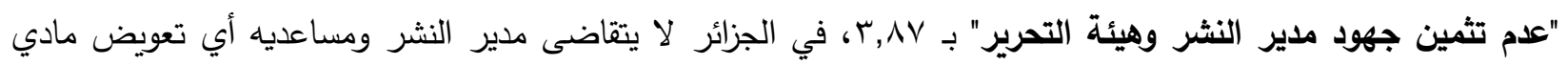
مقابل إدارة المجلة، ولعل الدافع الأساسي لاى أغلبهم هو تحقيق بعض المنافع الثخصية كاستغلال المجلة لنشر بحوثهم وبحوث 
أطراف أخرى، وكما هو معروف لاى الدجلات العريقة يمنع على هيئة النشر نشر أبحاثهم في مجلتهم، إلا أن بعض المجلات

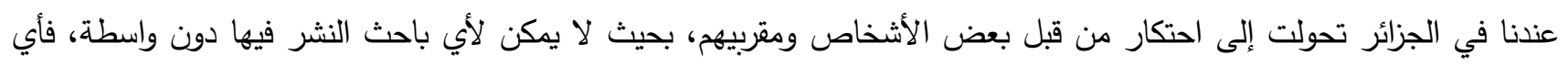

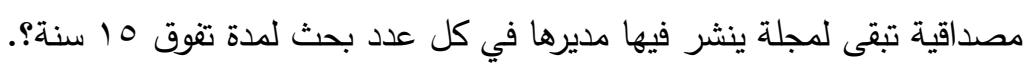

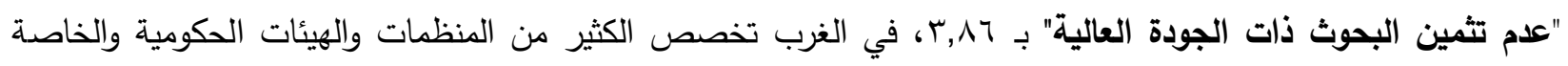
جوائز قيمة لأفضل البحوث المنشورة، كما يتم الإعلان عن مسابقات بشكل دوري لإجراء بحوث متخصصة لعلاج الجات مشكلات معينة،

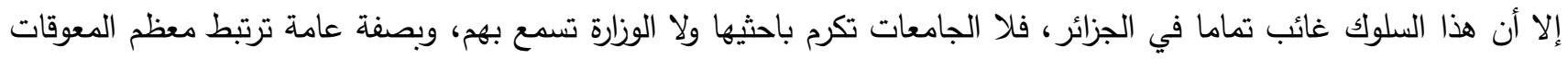
التمويلية بضعف الإنفاق الحكومي على البحث العلمي. جدول رقم (؛) المعوقات الثخصية للبحوث التربوية المنشورة في المجلات العلمية

\begin{tabular}{|c|c|c|c|c|}
\hline 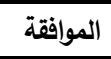 & 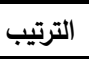 & 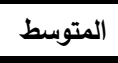 & المعوقات الشخصية & 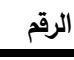 \\
\hline \multirow{6}{*}{ عالية } & 1 & 4,1692 & ضعف التحكم في اللغة الانجليزية & 1 \\
\hline & 4 & 4,0154 & عدم القدرة على تسديد رسوم النشر في المجلات الأجنبية & 2 \\
\hline & 6 & 3,8769 & التركيز على البحوث النظرية على حساب البحوث التطبيقية & 3 \\
\hline & 5 & 3,9231 & فردية الأبحاث وغياب البحث الجماعي & 4 \\
\hline & 2 & 4,1231 & ضعف التحكم في مختلف البرامج الإحصائية (مثل spss) & 5 \\
\hline & 3 & 4,1077 & الانشغال بأنشطة أخرى غير بحثية (كالتريس والإدارة) & 6 \\
\hline عالية & 2 & 4,0359 & المتوسط المرجح العام & \\
\hline
\end{tabular}

يوضح الجدول أعلاه أن أكثر المعوقات الثخصية يرتبط بـ "ضعف التحكم في اللفة الانجليزية" بمتوسط 7 ا, بـ بأهمية نسبية

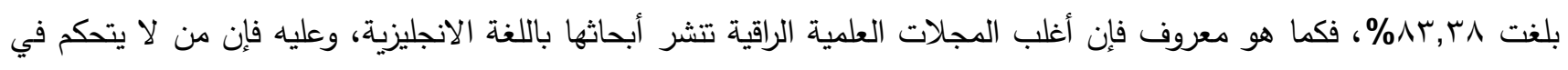

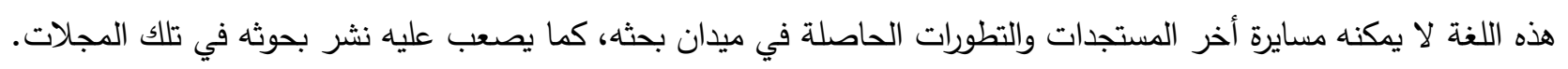

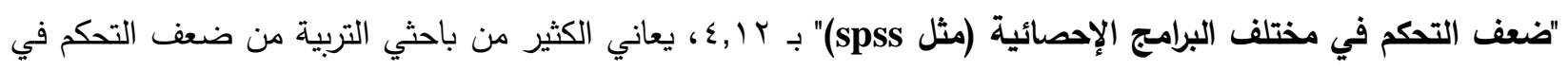

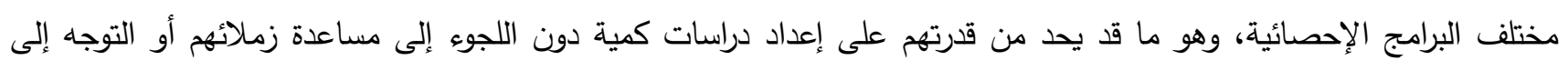
محلات تجارية لاستكمال الجزء التطبيقي من دراستهم، كما قد يؤدي ذلك إلى تلاعب بعض الإنه الباحثين بنتائج بحوثهم أو الميل لإعداد دراسات نظرية. "الانثغال بأنثطة أخرى غير بحثية (كالتدريس والإدارة)" بـ • , ,؛، وقد يرتبط ذلك بانشغال البعض بتدريس ساعات إضافية،

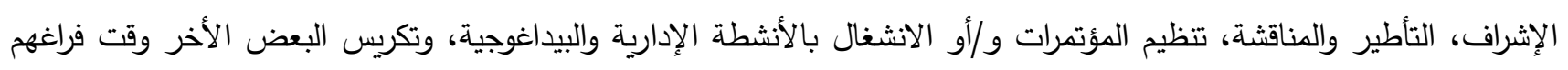

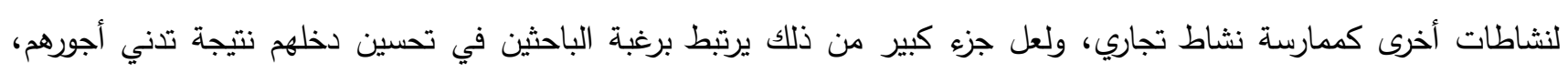
وبالتالي غاب البحث العلمي الأصيل وحلت مكانه الرداءة. "علدم القدرة على تسديد رسوم النثر في المجلات الأجنبية" بـ 1.,ع، فمن المتعارف عليه أن الكثير من المجلات الأجنبية

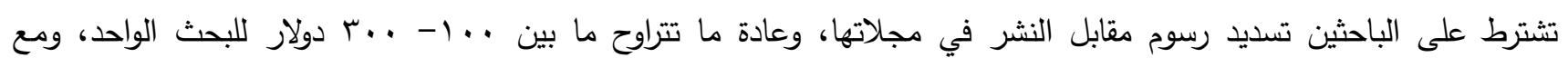

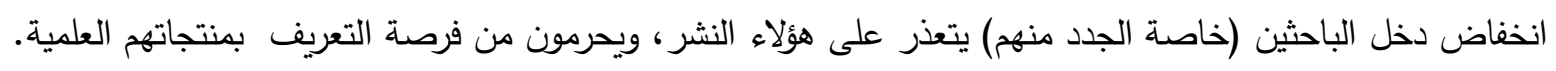

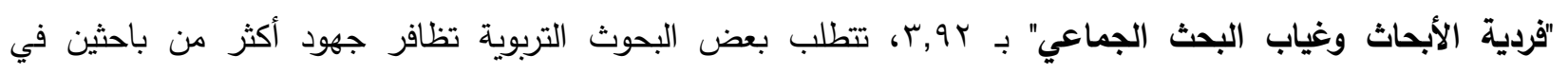

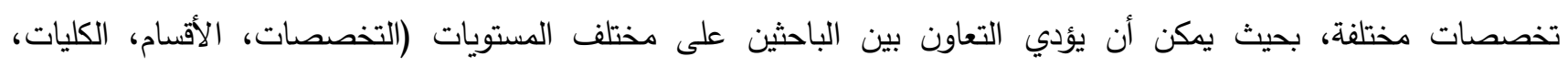

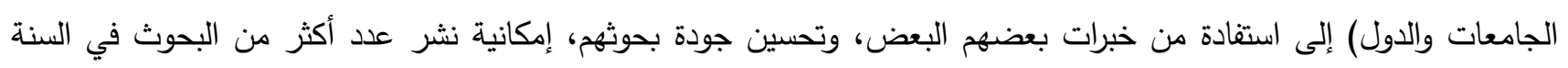
الواحدة. 
"التركيز على البحوث النظرية على حساب البحوث التطبيقية" بـ N, IV، وقد يعود ذلك إلى أحد الأسباب التالية: نقص البيانات المتوفرة حول بعض الظواهر التربوية، عدم توفر الإمكانيات اللازمة (المالية والمادية)، عدم التحكم في منهجية الدراسات التطبيقية، عدم الرغبة في بذل الوقت والجها وعدم مكافأة البحوث التطبيقية الرصينة.

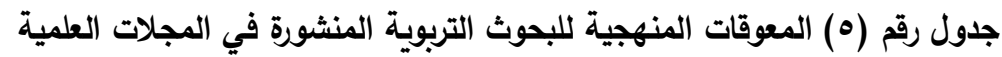

\begin{tabular}{|c|c|c|c|c|}
\hline 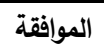 & الترتيب & المتوسط & المعوقات المنهجية & الرقم \\
\hline عالية & 5 & 4,1231 & عدم ملاءمة الأساليب الإحصائية الدستخدمة في قياس الدتغيرات & 1 \\
\hline \multirow{3}{*}{ ع الية جدا } & 2 & 4,2769 & عدم دقة أداة القياس (الآستبيان) & 2 \\
\hline & 1 & 4,4615 & عدم أصالة المواضيع المقدمة للنشر & 3 \\
\hline & 4 & 4,2462 & عدم ملاءمة وكفاية عينة الدراسة & 4 \\
\hline عالية & 6 & 3,9538 & ضعف مناقثة وتحليل النتائج & 5 \\
\hline عالية جدا & 3 & 4,2615 & ضعف التأصيل النظري للبحوث المقدمة للنشر & 6 \\
\hline عالية جدا & 1 & 4,2205 & المتوسط المرجح العام & \\
\hline
\end{tabular}

يتضح من خلال الجدول أن أولى المشكلات المنهجية التي يعاني منها الباحث التربوي هي "عدم أصالة المواضيع المقدمة

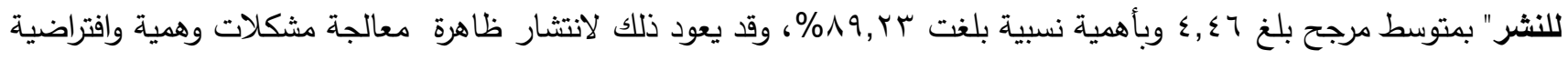
(مفتعلة وغير حقيقية) وأحيانا مستوحاة من دراسات أجنبية (مجرد عملية استتساخ)، ويغلب عليها طابع النمطية (تقليدية)، فكما هو ولئه

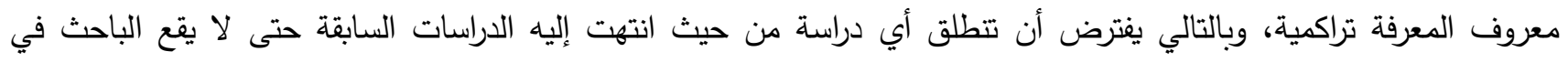
التكرار وحتى لا ينطلق من الفراغ ولا يورط نفسه في معالجة مسائل معزولة تكون بعيدة عن معالجة مشكلات تربوية واقعية وتئتئت

$$
\text { إلى أسس ومنطلقات صحيحة. }
$$

"علم دقة أداة القياس (الاستبيان)" بمتوسط V Y, ؟ ، لا يمتلك الكثير من الباحثين لقواعد بناء وصياغة الاستبيان الذي سوف

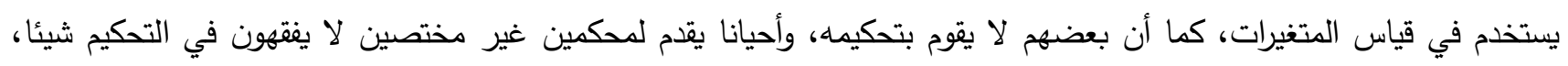

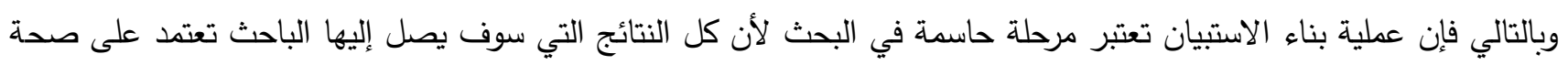
ودقة وثبات أداة القياس. "ضعف التأصيل النظري للبحوث المقدمة للنشر" بـ جr,ع، وقد يكون ذلك بسبب نقص المراجع ولكون أغلب المراجع باللغة

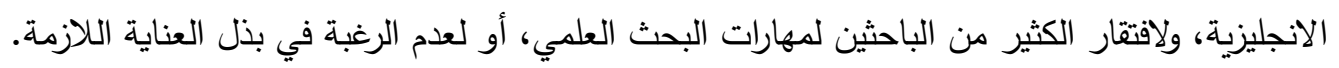

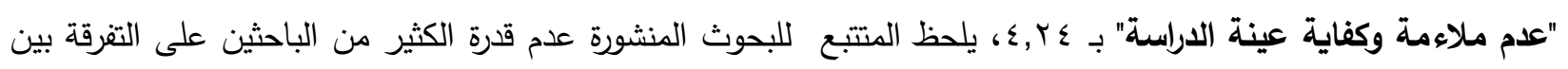

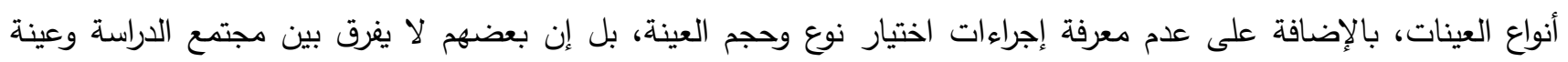
الدراسة، ولا شك أن الاختيار الخاطئ للعينة يقود إلى نتائج مضلافلة.

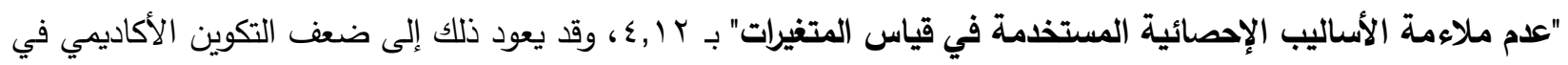
مقاييس المرتبطة بالمنهجية والإحصاء، وإلى ضعف التأطير في مرحلة الماجستير والدكتوراه، ولا يخفى أن اختيار أساليب إحصائية

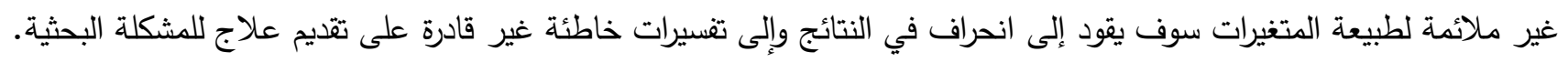
"ضعف مناقثة وتحليل النتائج" بمتوسط 90,9، وهو ما يعني اكتفاء الكثير من الباحثين بعملية تحليل سطحية للنتائج دون

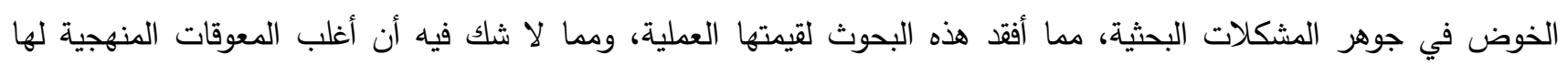
علاقة بضعف تكوين الباحث التربوي، والذي قد يعتبر أحيانا ضحية منظومة تعليمية فثلت في تزويده بالمهارات اللازمة. 
من جملة المعوقات الأخرى التي ذكرتها مفردات عينة الدراسة: تأثير الوضع السياسي العام على الرغبة في البحث، بيئة غير

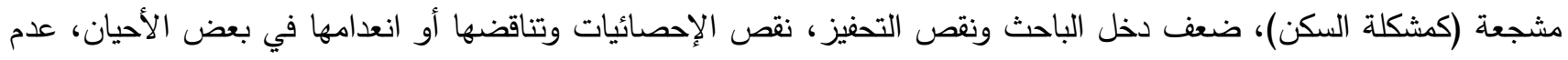
اشتراك الجامعات في قواعد المعلومات العالمية، غياب الخطط والسياسات، هجرة الأدمغة المؤطرة إلى الدول المتقدمة.

\section{r. اختبار فرضيات الدراسة:}

لقد تم الاعتماد على قاعدة القرار التالية في اختبار الفرضيات، فعند مستوى ثقة 90\% ومات ومستوى دلالة أكبر من أو

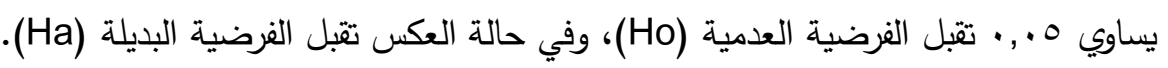

\section{• اختبار الفرضية الرئيسية الأولى:}

فo1: لا تختلف الأهمية النسبية لطبيعة معوقات نشر البحوث التربوية في المجلات العلمية من وجهة نظر باحثي التربية

في الجزائر.

Ho11: لا تختلف الأهمية النسبية للمعوقات التنظيمية والإدارية لنشر البحوث التربوية في المجلات العلمية من وجهة

$$
\text { نظر باحثي التزبية في الجزائر. }
$$

نمo12: لا تختلف الأهمية النسبية للمعوقات التمويلية لنشر البحوث التربوية المنشورة في المجلات العلمية من وجهة

$$
\text { نظر باحثي التربية في الجزائر. }
$$

Ho13: لا تختلف الأهمية النسبية للمعوقات الشخصية لنشر البحوث التربوية المنشورة في المجلات العلمية من وجهة

$$
\text { نظر باحثي التربية في الجزائر. }
$$

Ho14: لا تختلف الأهمية النسبية للمعوقات المنهجية لنشر البحوث التربوية المنشورة في المجلات العلمية من وجهة

\begin{tabular}{|c|c|c|c|}
\hline النتيجة & الدلالة (Sig) & قيمة t & رقم الفرضية \\
\hline رفض & ,000 & 23.891 & Hol \\
\hline
\end{tabular}

$$
\text { نظر باحثي التربية في الجزائر. }
$$

جدول رقم (†) اختبار الفرضية الرئيسية الأولى

بما أن قيمة T المحسوبة بلغت 9.^,بr في حين بلغ مستوى الدلالة ...,., فإننا نرفض الفرضية العدمية (Ho)، ونقبل الفرضية البديلة (H1) والقائلة بـ "اختلاف الأهمية النسبية لطبيعة معوقات نشر البحوث التربوية في المجلات العلمية عند أخذ هذه المعوقات بصورة مجتمعة"، وهذا يعني اختلاف درجات تأثير كل مجموعة من المعوقات المدروسة على نشر البحوث التربوية في المجلات العلمية، وقد يعزى هذا الاختلاف إلى اختلاف درجة تعقد البحث التربوي وعدد البحوث المنشورة، واختلاف المهارات

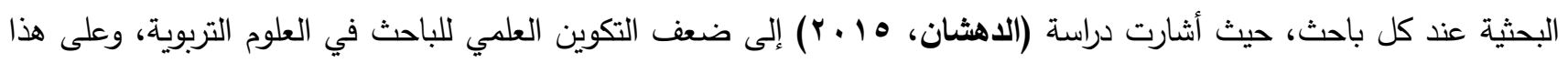

\begin{tabular}{|c|c|c|c|c|}
\hline النتيجة & الدلالة (Sig) & قيمة t & المتوسط المرجح & رقم الفرضية \\
\hline رفض & ,000 & 11,782 & 3,8436 & Ho11 \\
\hline رفض & ,000 & 20,096 & 4,0179 & Ho12 \\
\hline رفض &, 000 & 18,835 & 4,0359 & Ho13 \\
\hline رفض & ,000 & 28,116 & 4,2205 & Ho14 \\
\hline
\end{tabular}
الأساس يتوجب التركيز على مجموعة المعوقات الأكثر تأثيرا وهي المعوقات المنهجية وعند تذليلها يتوجب إزالة المعوقات الثخصية

جدول رقم (V) اختبار الفرضيات الجزئية للفرضية الرئيسية الأولى 


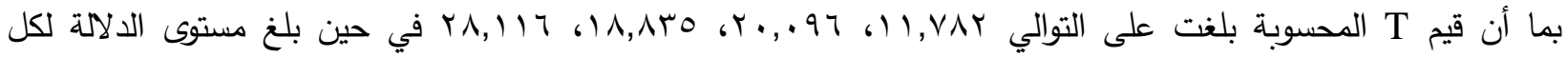

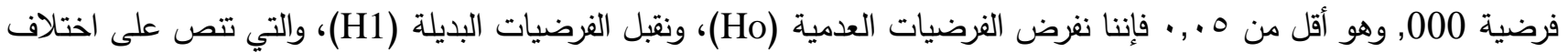

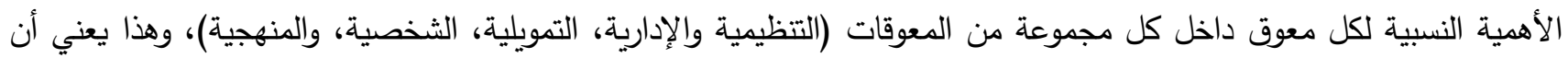

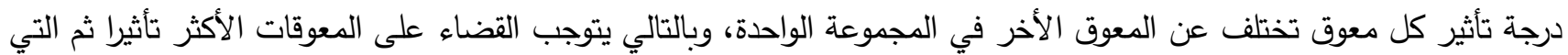

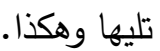

\section{• اختبار الفرضية الرئيسية الثانية:}

Ho2 لا يوجد اختلاف ذو دلالة إحصائية في الأهمية النسبية لطبيعة معوقات نشر البحوث التربوية في المجلات العلمية

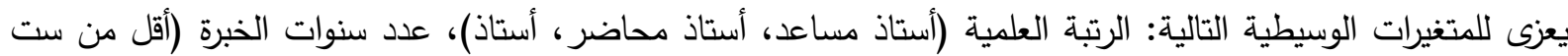
سنوات، من ست إلى اثثي عشر سنة، أكثر من اثني عشر سنة)، دور الباحث في عملية النشر (محكم، باحث، مسؤول

نشر).

جدول رقم (^) اختبار الفرضيات الفرعية للفرضية الرئيسية الثانية

\begin{tabular}{|c|c|c|c|c|c|c|}
\hline النتيجة & الالاية (Sig) & F قيمة F & درجة الحرية & المربعات & المصلر & المتغيرات \\
\hline \multirow{3}{*}{ لا توجد فروقات } & \multirow{3}{*}{ •,Tr. } & \multirow{3}{*}{$\cdot, \varepsilon \wedge 1$} & r & $\cdot, 111$ & بين المجموعات & \multirow{3}{*}{ الرتبة } \\
\hline & & & $\pi$ & $V, T \cdot V$ & خارج المجموعات & \\
\hline & & & $T \varepsilon$ & $V, V Y_{0}$ & المجموع & \\
\hline \multirow{3}{*}{ لا توجد فروقات } & \multirow{3}{*}{$\cdot, 1 V_{0}$} & \multirow{3}{*}{$1, \times 91$} & $r$ & . $\varepsilon r Y$ & بين المجموعات & \multirow{3}{*}{ الخبرة } \\
\hline & & & Tr & $V, r \cdot r$ & خارج المجموعات & \\
\hline & & & $7 \varepsilon$ & $V, V Y O$ & المجموع & \\
\hline \multirow{3}{*}{ لا توجد فروقات } & \multirow{3}{*}{$\cdot, 119$} & \multirow{3}{*}{$r, \cdot V$} & r & $\cdot .01 r$ & بين المجموعات & \multirow{3}{*}{ الدور } \\
\hline & & & Tr & $V, r)$ & خارج المجموعات & \\
\hline & & & $7 \varepsilon$ & $V, V Y O$ & المجموع & \\
\hline
\end{tabular}

تم استخدام اختبار تحليل التباين الأحادي (One Way ANOVA) لاختبار الفرضيات الفرعية للفرضية الثانية، وتشير المعطيات الإحصائية في الجدول رقم (^) إلى عدم وجود فروق ذات دلالة إحصائية في طبيعة المعوقات التي تواجه باحثي التربية عند الرغبة في نشر بحوثهم في المجلات العلمية عند أخذ هذه المعوقات بصورة مجتمعة تعزى للمتغيرات الوسيطية التالية: الرتبة،

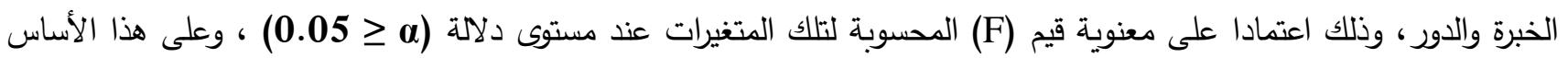

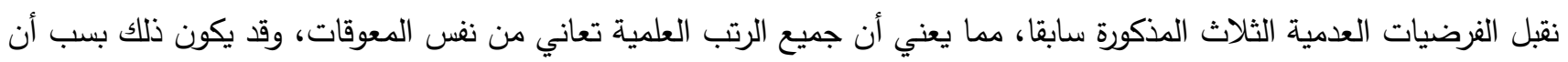

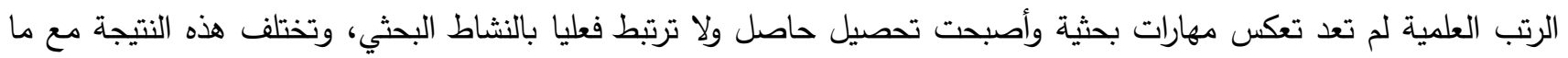

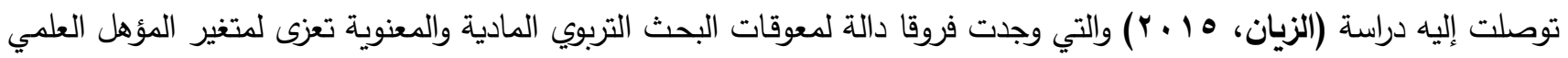

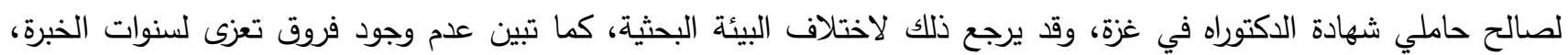

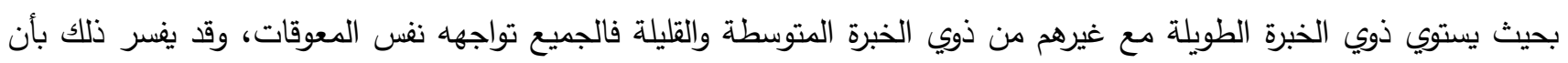
سنوات العمل أصبحت تعكس أقدمية في التدريس وليس خبرة في البحث وربما يرجع ذلك إلى نقص التحفيز وارتباط النشر بالترقية

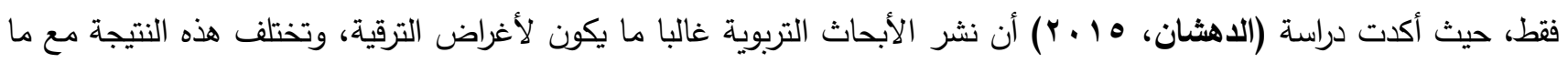

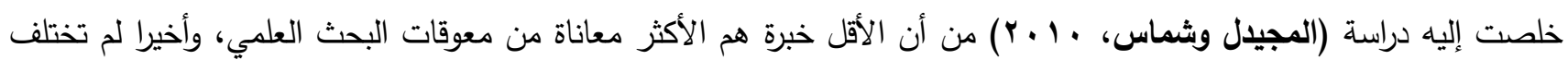

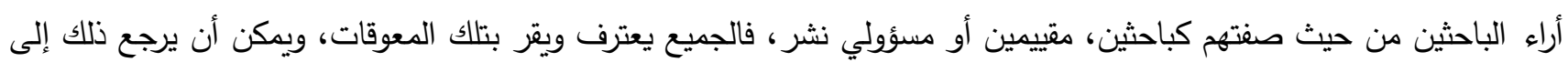
كون جميع المستجوبين لديهم نفس التجارب مع النشر ويدركون جيدا تعقد وصعوبة إجراءات النشر في الجزائر ، حيث تدعم هذه 
النتيجة ما توصلت إليه دراستي (مولوج، ؛ l ـ ب) من اعتماد بعض الباحثين على العلاقات الثخصية في نشر بحوثهم في المجلات العلمية، ودراسة (الجرجاوي وحماد، ه . . ب) حول تأثير العلاقات الثخصية بين القائمين على تقييم البحوث.

رابعاً: نتائج وتوصيات الدراسة

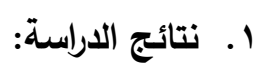

أسفرت هذه الدراسة عن النتائج التالية:

• اختلاف الأهمية النسبية لطبيعة معوقات نشر البحوث التربوية في المجلات العلمية عند أخذ هذه المعوقات بصورة

مجتمعة وعند أخذها بصورة مستقلة.

تؤثر المعوقات المنهجية بدرجة كبيرة جدا على نشر البحوث التربوية في المجلات العلمية وذلك بأهمية نسبية بلغت

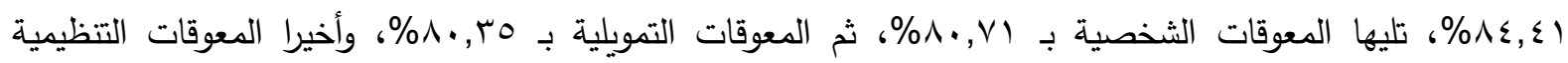

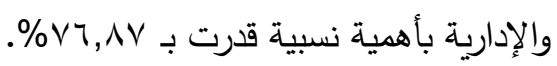

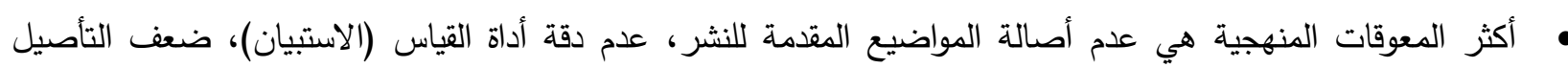
النظري للبحوث المقدمة للنشر وعدم ملاءمة وكفاية عينة الدراسة. هأكثر المعوقات الثخصية تتمثل في ضعف التحكم في اللغة الانجليزية، ضعف التحكم في مختلف البرامج الإحصائية والانشغال بأنشطة أخرى غير بحثية كالتدريس والإدارة. • أكثر المعوقات التمويلية هي عدم كفاية الميزانيات المخصصة للمجلات العلمية، عدم تثمين جهود المحكمين، نقص بتصن التجهيزات والمعدات البحثية وانعدام الرعاية التمويلية. أكثر المعوقات التتظيمية والإدارية هي انتشار الاعتماد على الوساطة في نشر البحوث، التأخر في تقييم ونشر البحوث، غياب معايير واضحة لقبول البحوث وعدم الواقعية في تحكيم البحوث. لا يوجد فروقات دلالة إحصائيا في الأهمية النسبية لطبيعة معوقات نشر البحوث التربوية في في المبية المجلات العلمية تعزى

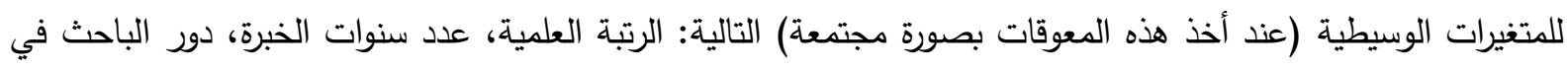
عملية النشر (محكم، باحث، مسؤول نشر).

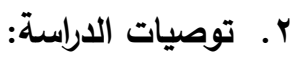
في ضوء النتائج المتوصل إليها نوصي مختلف الأطراف المعنية بالأتي: الرفع من الكفاءة البحثية للباحثين، من خلال إجراء دورات تكوينية متخصصة يجريها باحثين كبار وعلماء معروفين في الساحة العلمية. تخصيص ميزانيات كافية للمجلات العلمية، تأخذ بعين الاعتبار تكاليف إدارة النشر، والتحكيم والطبع، وإنشاء مطبعة وطنية خاصة بالمجلات العلمية لتخفيض تكاليف الطبح. تشجيع النشر الاككتروني للمجلات العلمية، وإلزام مختلف الهيئات العلمية لقبول تلك المجلات في الترقية وفق شروط مضبوطة، بالإضافة إلى معاقبة من تثبت عليه السرقة العمية. تشجيع الباحثين على كتابة بحوثهم باللغة الانجليزية ونشر بحوثهم في مجلات عالمية رائدة، وذلك من خلال تطوير مهاراتهم اللغوية ورصد جوائز قيمة للبحوث المنشورة في مجلات راقية بلية. إنشاء مجلات متخصصة في المجال التربوي ووضع شروط علمية صارمة للنشر فيها مع توفير نموذج/ قالب المقال (template) ) وانتقاء لجنة علمية تتوفر في أعضائها شروط الجودة، مع ضرورة تثمين جهود المحكمين لتحفيزهم. قيام كل مجلة علمية بإصدار أعداد خاصة تتناول قضايا محددة وتصدر بشكل مستمر ، وتوجيه الدعوة مبكرا للمهتمين لنشر بحوثهم، وذلك لمنحهم الوقت الكاف لإعداد بحوث أصيلة. 
تتاولت الدراسة الحالية البحث في معوقات نشر البحوث التربوية في المجلات العلمية في الجزائر ، وبذلك تكون قد

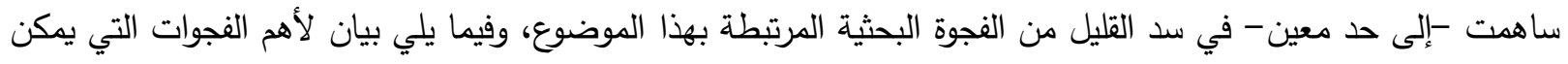
للباحثان و /أو لباحثين آخرين تناولها مستقبلا: معوقات نشر البحوث التربوية في المجلات الأجنبية المتخصصة، أثر الالتزام الأخلاقي لباحثي التربية على جودة البحوث المنشورة في المجلات، أثر الحرية الأكاديمية للباحث التربوي على جودة البحث.

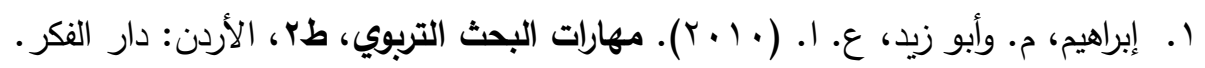

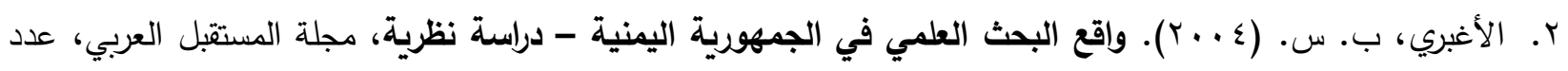

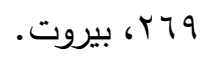

r. بالخيور ، ش. ع. ا. (997 (1)). فرضيات البحث: دراسة تقويمية مقارنة لأساليب اشتقاق وصياغة الفرضيات وتحقيقها

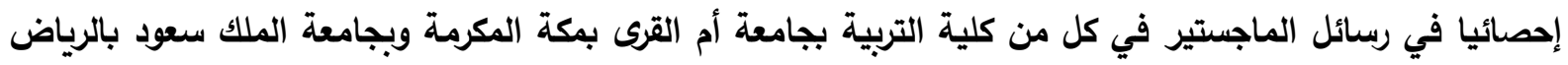

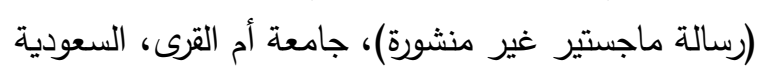

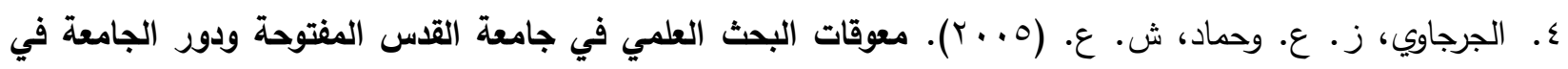

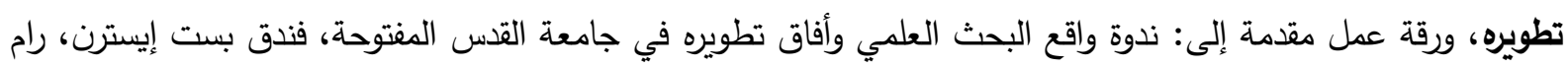

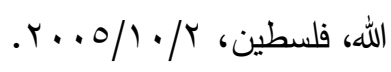
ه. الخليلي، خ. ي. (· (ب). التحديات التي تواجه البحث التربوي في الوطن العربي، بحث مقدم إلى المؤتمر العلمي العاشر بعنوان: البحث التربوي في الوطن العربي "رؤى المستقبل"، كلية التربية، جامعة الفيوم، مصر ، المجلد الأول: . $\{19-\varepsilon \cdot r$

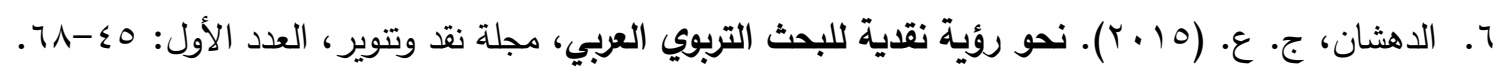

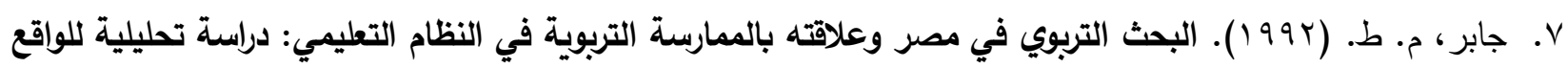

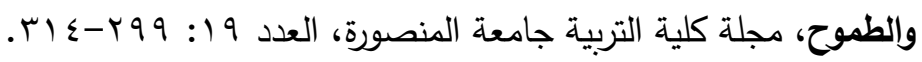

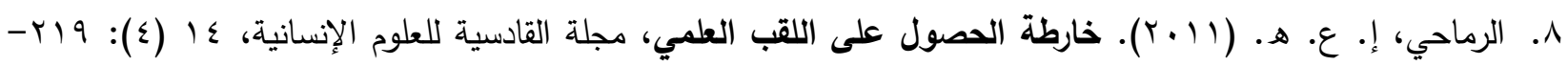
. $r \leqslant \wedge$ 9. الزيان، م. (1) (1 ب). معوقات البحث التربوي بمحافظات غزة، بحث مقدم إلى مؤتمر : البحث العلمي مفاهيمه، أخلاقياته،

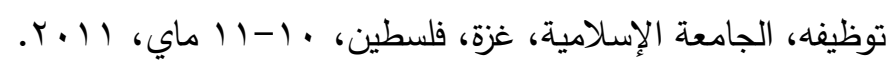

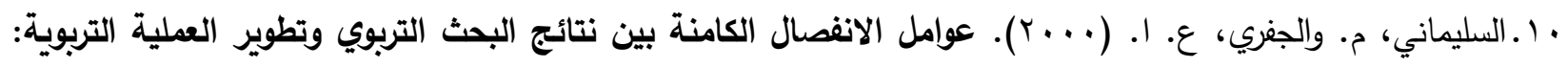

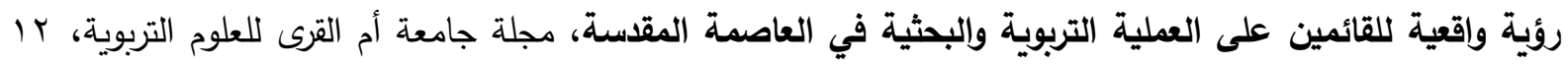

1)

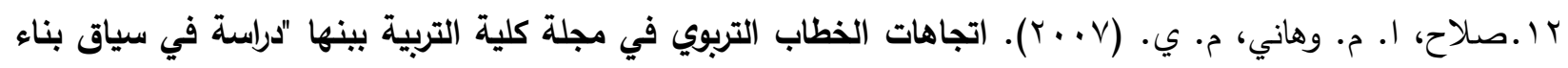

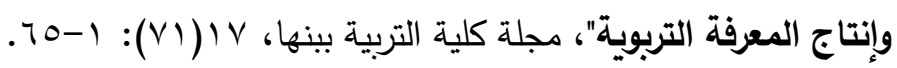
با ـالثرع، إ. والزعبي، ط. (1) (1). مشكلات البحث التربوي من وجهة نظر أعضاء هيئة التدريس في كليات العلوم

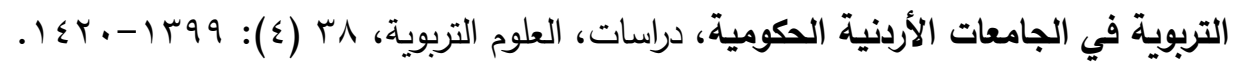




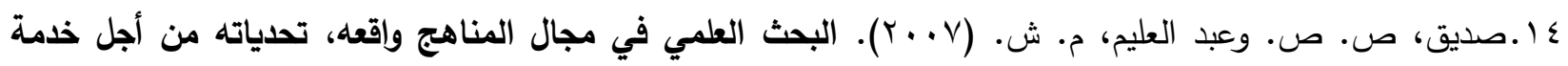
قضايا الأمة، بحث مقدم إلى المؤتمر العلمي الأول بعنوان: توجيه بحوث الجامعات الإسلامية في خدمة قضايا الأمة،

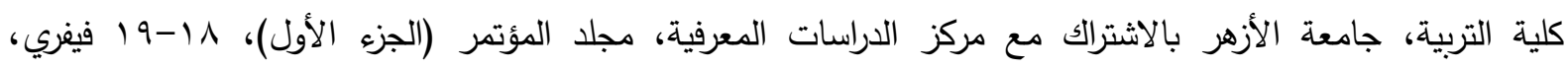

1 ـ.طوطاوي، ز. (ب99 1). الجو التنظيمي السائد في الجامعة الجزائرية وعلاقته برضا الأساتذة (رسالة ماجستير غير منشورة)، معهد علم النفس وعلوم التربية، جامعة الجزائر .

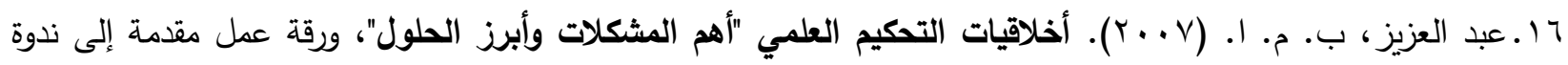

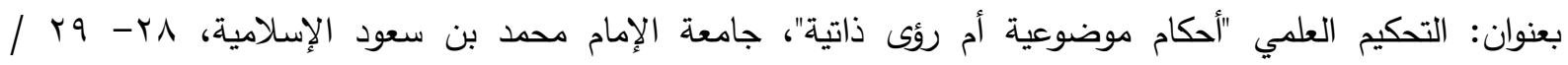
$.1 \leq r \wedge / 1\}$

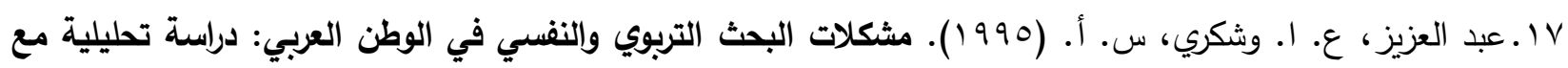

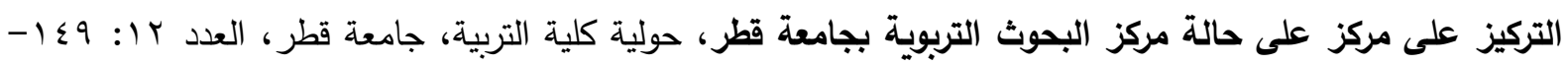
.19.

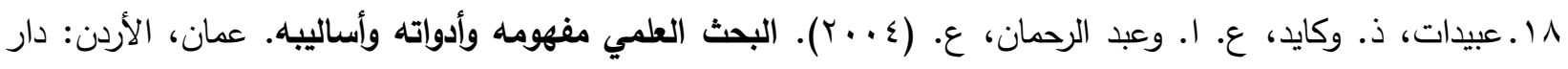
الفكر . 9 1. العنيزي، ي. ويونس، س. وسلام، ع. ا. والرشيدي، س. (9991). مناهج البحث التربوي بين النظرية والتطبيق،

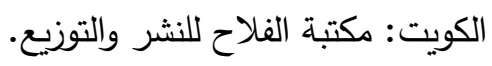

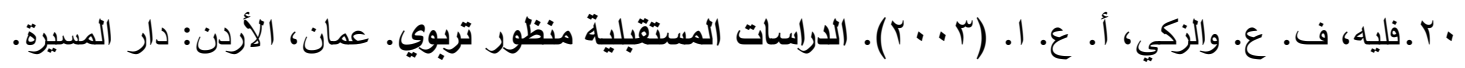

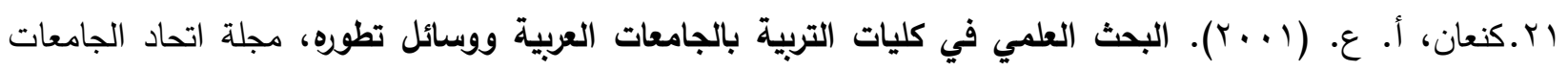

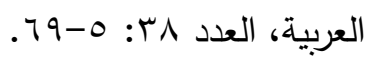
r r.المجيدل، ع. ا. (999 (19). المشكلات الأكاديمية لأعضاء الهيئة التدريسية في جامعة دمشق، مجلة جامعة دمشق، .90-乏r: $:(r) 10$

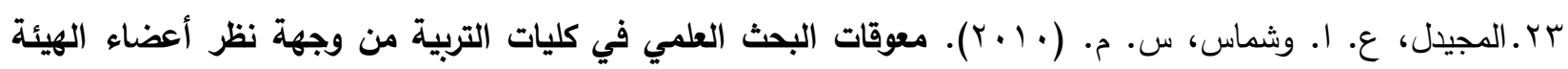

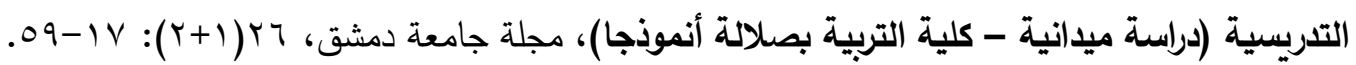

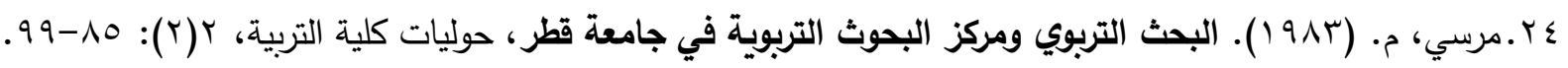

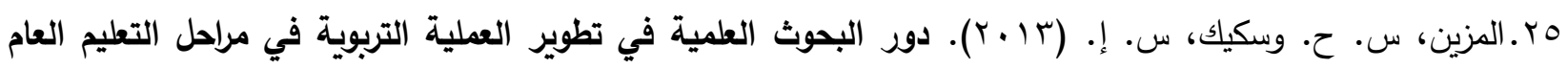

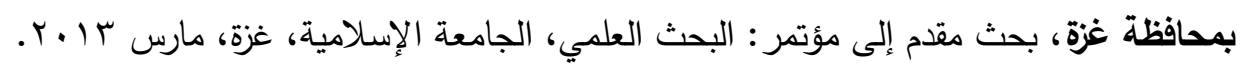

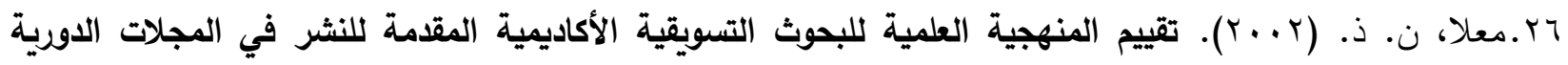

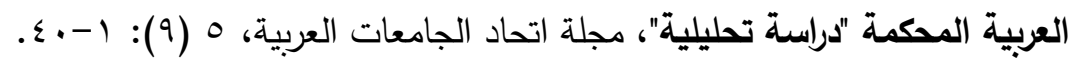

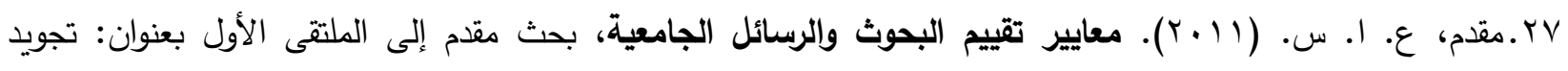

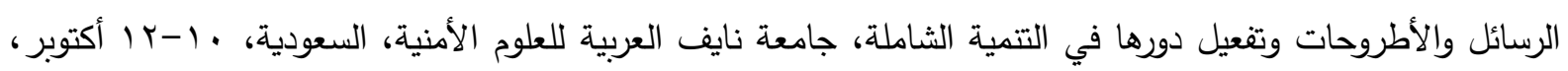
r. II

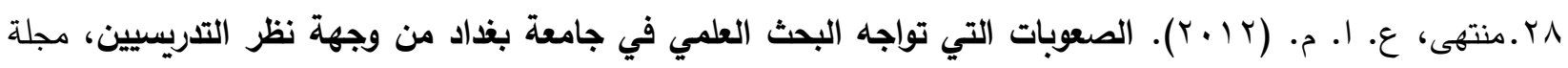

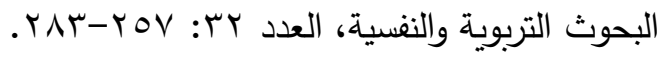


9. .المهدي، ي. ا. والفهدي، ر. س. ولاشين، ح. ع. ا. والثنفري، ع. ا. م. (ع ( • ب). آليات مقترحة لتفعيل دور البحث التربوي في صنع السياسة التعليمية بسلطنة عمان من وجهة نظر الباحثين والممارسين، المجلة الدولية التربوية

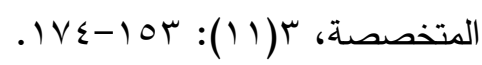

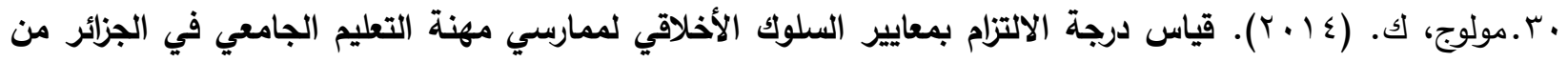

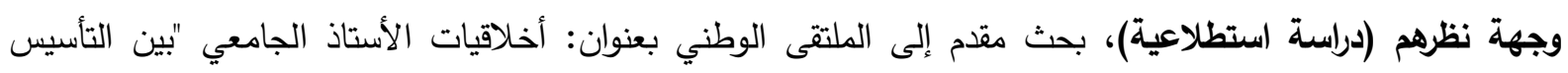

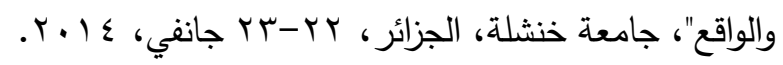

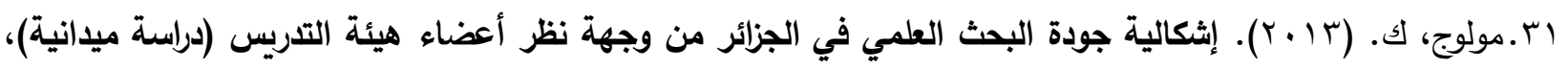

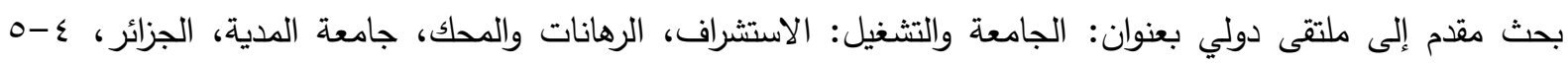

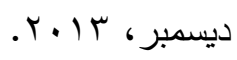

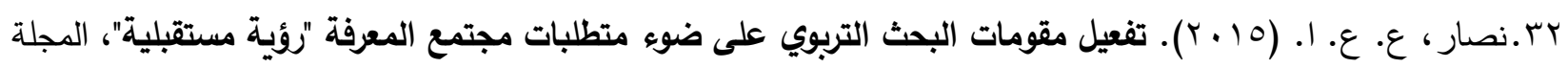

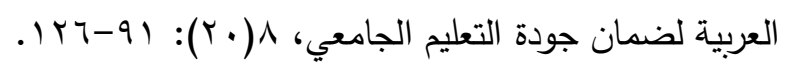

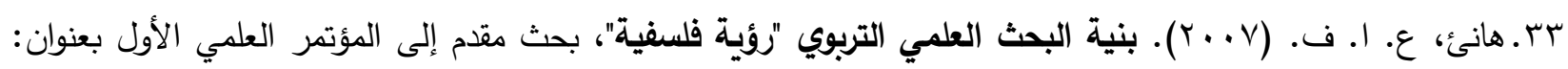

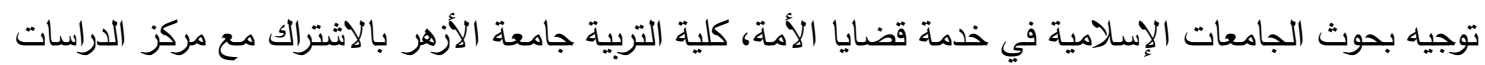

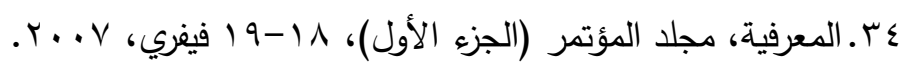

ثانياً: المراجع الأجنبية:

[1] Cohen, L. Manion, L., \& Morrison, K. (2005). Research Methods in Education (5th Edition). London: Routledge Falmer.

[2] Day, Robert, A. (1983). How to Write and Publish a Scientific Paper, Philadelphia: ISI Press.

[3] Levin, H. M. (1991). Why isn't educational research more useful? In D. S. Anderson and B. J. Biddle (eds) Knowledge for Policy: Improving Education through Research, London: Falmer, pp. 70-78.

[4] Winch, C. (2001). Accountability and Relevance in Educational Research, Journal of Philosophy of education. 35 (03): 443-459. 


\title{
Obstacles of Publishing Educational Researches in Scientific Journals
}

\author{
Kamel Mouloudj \\ Lecturer Class A, Faculty of Economics - University Yahia fares of Medea - Algeria \\ kmouloudj@yahoo.fr \\ Farida Mouloudj \\ PhD student, Faculty of Arts \& Languages University Ali Lounici of Blida - Algeria \\ famouloudj@yahoo.com
}

\begin{abstract}
:
The present study aimed to determine the relative importance to obstacles of publishing educational researchs in scientific journals. To achieve this was, we used a convenience sample of 65 education researchers in various Algeria's universities. Descriptive analytical approach was used, The results indicated that most significant obstacle are the methodological obstacles with a relative importance amounted to $84.41 \%$; followed by personal obstacles at $80.71 \%$, then financing obstacles at $80.35 \%$, and finally organizational and administrative obstacles with relative importance estimated at $76.87 \%$. The results also showed that no statistically significant differences of a relative importance to obstacles of publishing educational researchs in scientific journals through intermediate variables: academic Rank, years of experience, role of the Researcher in the Publication Process (Arbitrator, Researcher, Publishing Officer). And finally the study presented some recommendations can help overcome the difficulties of publishing educational research in scientific journals.
\end{abstract}

Keywords: educational research, obstacles, scientific journals, Algeria. 